\title{
Elucidation of Adsorption Mechanisms And Mass Transfer Controlling Resistances During Single And Binary Adsorption of Caffeic And Chlorogenic Acids
}

Eyden S. Hernández-Padilla

Universidad Autónoma de San Luis Potosí: Universidad Autonoma de San Luis Potosi

Ana I. Zárate-Guzmán

Universidad Autónoma de San Luis Potosí: Universidad Autonoma de San Luis Potosi

Omar González-Ortega

Universidad Autónoma de San Luis Potosí: Universidad Autonoma de San Luis Potosi

Erika Padilla-Ortega

Universidad Autónoma de San Luis Potosí: Universidad Autonoma de San Luis Potosi

Azael Gómez-Durán

Universidad Autonoma de San Luis Potosi Facultad de Ciencias Quimicas

Pablo Delgado-Sánchez

Universidad Autonoma de San Luis Potosi Facultad de Agronomia y Veterinaria

Angélica Aguilar-Aguilar

Universidad Autonoma de San Luis Potosi Facultad de Ciencias Quimicas

Farid B. Cortés

Universidad Nacional de Colombia Sede Medellín: Universidad Nacional de Colombia Sede Medellin

Raul Ocampo-Perez ( $\nabla$ raul.ocampo@uaslp.mx )

Universidad Autonoma de San Luis Potosi

\section{Research Article}

Keywords: Caffeic acid, chlorogenic acid, binary adsorption, granular activated carbon.

Posted Date: August 23rd, 2021

DOl: https://doi.org/10.21203/rs.3.rs-802929/v1

License: (c) (i) This work is licensed under a Creative Commons Attribution 4.0 International License. Read Full License

Version of Record: A version of this preprint was published at Environmental Science and Pollution Research on December 1st, 2021. See the published version at https://doi.org/10.1007/s11356-021- 
17737-3. 

CONTROLLING RESISTANCES DURING SINGLE AND BINARY ADSORPTION

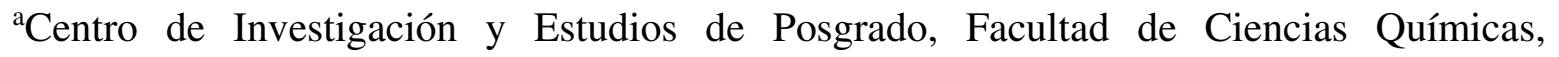
9 Universidad Autónoma de San Luis Potosí, San Luis Potosí 78260, México.

10 bLaboratorio de Biotecnología, Facultad de Agronomía y Veterinaria, Universidad 11 Autónoma de San Luis Potosí, Soledad de Graciano Sánchez, San Luis Potosí, Mexico.

$12{ }^{\mathrm{C}}$ Grupo de Investigación en Fenómenos de Superficie - Michael Polanyi, Facultad de Minas, 13 Universidad Nacional de Colombia-Sede Medellín, Colombia.

14

15

16

17

18

*To whom correspondence should be addressed: Tel: 52-4448132157. e-mail: raul.ocampo@uaslp.mx. 


\section{HIGHLIGHTS}

28

29 - Adsorption and mass transfer mechanisms of phenolic acids on GAC was elucidated.

30

31

32

33

34

35

36

37

38

39

40

41

42

43

44

45

46

47

48

49

50

51

52

53
- Adsorption of both acid compounds was governed by $\pi-\pi$ and electrostatic interactions

- Binary adsorption of caffeic acid and chlorogenic acid is antagonistic in nature

- Pore volume and surface diffusion mechanisms play an important role during adsorption 
55 NOMENCLATURE

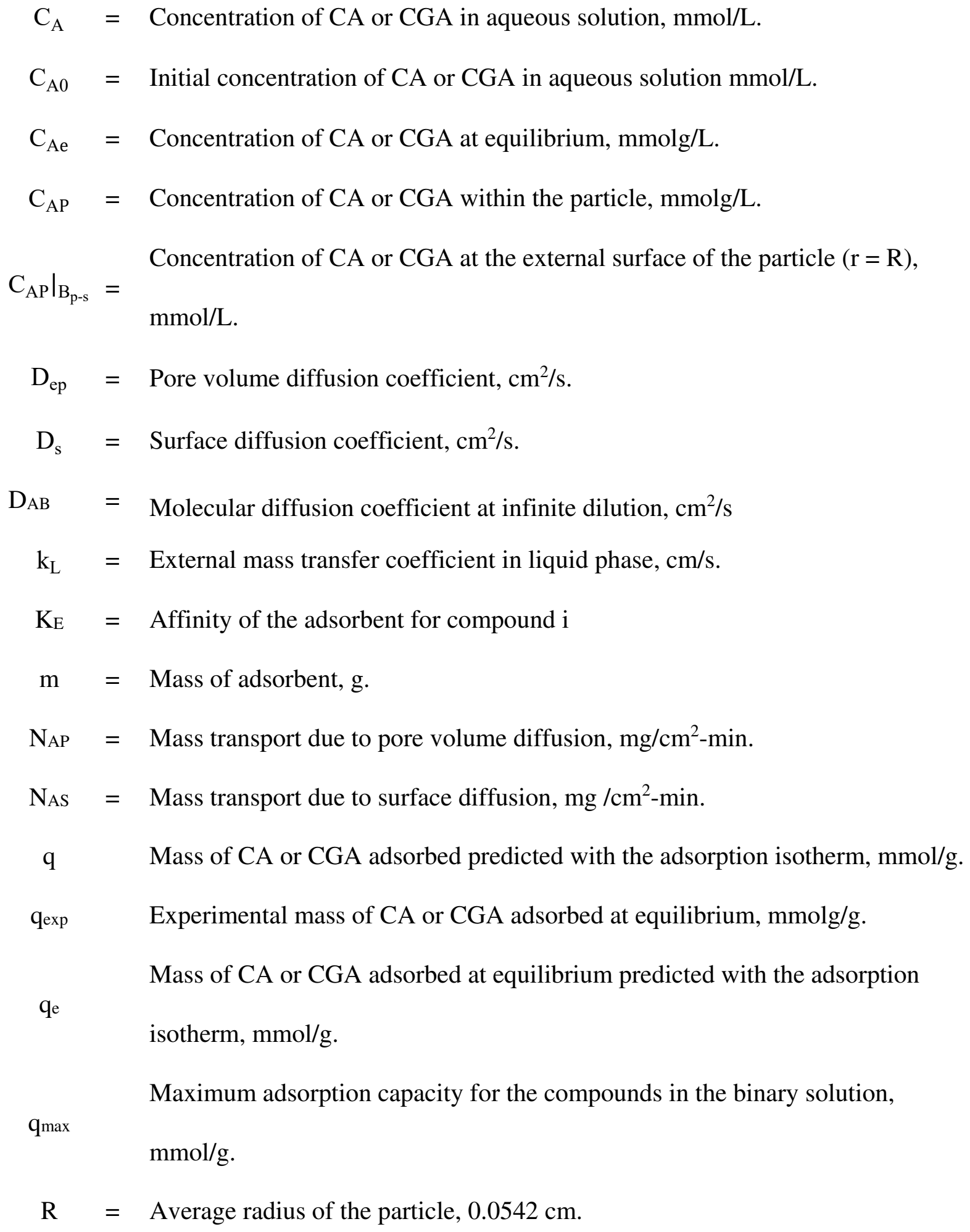


$\mathrm{S}=$ External surface area per mass of adsorbent, $\mathrm{cm}^{2} / \mathrm{g}, \mathrm{S}=3 / \mathrm{R} \rho_{\mathrm{p}}$.

$\mathrm{V}=$ Volume of the solution, $\mathrm{mL}$.

\section{Greek symbols}

$$
\begin{aligned}
\varepsilon_{\mathrm{p}} & =\text { Void fraction of particles } \\
\rho_{\mathrm{p}} & =\text { Density of adsorbent particles, } \mathrm{g} / \mathrm{cm} . \\
\tau & =\text { Tortuosity factor }
\end{aligned}
$$

56 
59 In this work, the potential of activated carbon to remove caffeic and chlorogenic acids was

60 investigated. The study focused on evaluating the single and binary adsorption equilibrium,

61 as well as investigating the mass transfer resistances present during the process by applying

62 kinetic and diffusional models for a future scale-up of the process. For both compounds, the

63 single adsorption equilibrium was studied at $\mathrm{pH}$ values of 3,5 , and 7 . The experimental

64 adsorption isotherms were interpreted using the Langmuir and Freundlich models, obtaining

65 maximum adsorption capacities of 1.33 and $1.62 \mathrm{mmol} / \mathrm{g}$ for caffeic and chlorogenic acid,

66 respectively. It was found that the adsorption mechanisms for both compounds was derived

67 from $\pi-\pi$ and electrostatic interactions. Also, the binary adsorption equilibrium was

68 performed and the experimental data were interpreted using the extended multicomponent

69 Langmuir model. The results evidenced that the binary adsorption of caffeic acid and

70 chlorogenic acid is antagonistic in nature. The application of the first and second order kinetic

71 models showed that the latter interpreted better the experimental data, obtaining R2 values

72 close to one. Finally, the experimental adsorption rate data were interpreted by a diffusional

73 model, finding the presence of different mass transfer resistances during the adsorption

74 process. For both compounds, intraparticle diffusion mechanisms were meaningful.

75

76 Keywords: Caffeic acid, chlorogenic acid, binary adsorption, granular activated carbon.

77

78

79

80 


\section{INTRODUCTION}

Caffeic and chlorogenic acids are phenolic compounds with beneficial properties for the human health; they have potent antioxidant, antiviral, anti-inflammatory, and antirheumatic activities (Singleton and Cilliers 1991). Moreover, both compounds can be used to synthesize drugs to combat neurodegenerative, cardiovascular, or carcinogenic diseases (Chang et al. 2010). These acids are widely distributed in vegetables, fruits, and herbs (e.g. artichokes, peanuts, and cinnamon) (Farah and Donangelo 2006). They are also present in coffee grains of the residual waters derived from the production of coffee (J.E. Braham and R. Bressani 1970).

Mexico possesses the $11^{\text {th }}$ place as coffee producer and the $12^{\text {th }}$ place as exporter with a cultivation area of 1,584,451 acres worldwide (J.E. Braham and R. Bressani 1970). Evidently, this production rate has as consequence an increase in the generation of wastewater derived from the production of coffee. This wastewater has a high content of organic matter with elevated acidity due to the presence of caffeic, chlorogenic, quinic, and acetic acids (J.E. Braham and R. Bressani 1970). Therefore, it is always relevant to evaluate the existent technologies for the remotion of these valuable compounds. In this context, adsorption is a cheap and simple to operate method with a variety of adsorbents that include starch (Simanaviciute et al. 2017), silica (Moritz and Geszke-Moritz 2016), ionic liquids (Du

et al. 2011), macroporous resins (Jiang et al. 2020), and chitosan (Liudvinaviciute et al. 2020).

Few studies exist in the literature dealing with the adsorption of caffeic and chlorogenic acids. Furthermore, these studies are focused on the individual adsorption of one of these compounds, ignoring not only the behavior of binary systems but the diffusional effects during the adsorption process. Simanaviciute et al. (2017) evaluated the adsorption, 
at equilibrium, of caffeic and chlorogenic acids at different temperatures on crosslinked cationic starch. Their results established that the maximum adsorption capacity was 1.5 -fold higher for chlorogenic acid than for caffeic acid; moreover, these authors determined that electrostatic interactions played a predominant role during the adsorption of both acids. The adsorption of caffeic acid over the silica SBA-15 and MCF functionalized with APTES (3aminopropyltriethoxysilane) and AEAPTMS ([3-(2-aminoethylamino) propyl] triimethoxysilane) was investigated by Moritz and Geszke-Moritz (2016) using 2-propanol as solvent. The results established that the adsorption capacity was higher for the AEAPTMSfunctionalized SBA-15 and MCF (192.3 and $161.3 \mathrm{mg} / \mathrm{g}$, respectively) when compared to the APTES-functionalized counterparts (125.0 and $113.6 \mathrm{mg} / \mathrm{g}$, respectively). Jiang et al. (2020) studied the equilibrium, kinetics, and desorption of chlorogenic acid in 10 different types of macroporous resins (AB-8, D4020, HPD-722, HPD-300, HPD-100, NKA, NKA-II, NKA-9, S-8, and X-5). The results indicated that polar resins had higher adsorption capacity when compared to nonpolar resins, the resin NKA-II showed the highest adsorption capacity (35.6 mg/g). Finally, these authors showed that the pseudo-second order model properly interpreted the experimental data of adsorption kinetics.

Unlike the adsorbents employed in the literature, activated carbon presents high specific area and a variety of functional groups that could enhance the adsorption of caffeic and chlorogenic acids. The caffeic and chlorogenic acids are natural hydroxycinnamic acids that are common in beverages derived from plants such as coffee (Wang and Ho 2009). As consequence, both compounds will exist in water and compete for the adsorption sites in the adsorbent. In a competitive adsorption situation, the adsorption of one component could be diminished, favored, or unaffected by the presence of other components (Srivastava et al. 2006); these types of competitive situations are named antagonistic, cooperative or synergic, 
129 and noninteractive, respectively (Carrales-Alvarado et al. 2018). To the best of our 130 knowledge, neither the competitive adsorption of caffeic and chlorogenic acids nor the use

131 of models of multicomponent adsorption have been studied. For this reason, the objective of 132 the present work is to investigate, for the first time, the potential of activated carbon for the 133 removal of caffeic and chlorogenic acids evaluating the individual and binary adsorption. 134 Additionally, the adsorption rate of both compounds was studied in-depth, along with the 135 mass transfer mechanisms during the adsorption process using kinetic and diffusional models 136 for a future scale-up of the process.

\section{MATERIALS AND METHODS}

\subsection{Adsorbates}

140 In this work, caffeic (CA) and chlorogenic (CGA) acids were acquired from Merck, bot with 141 a purity $\geq 95 \%$. Their physicochemical properties are presented in Table 1 . From their values 142 of $\mathrm{pKa}$, the speciation diagrams shown in Figure 1 were constructed. For the case of CGA 143 (Figure 1a), it exists as neutral molecule at $\mathrm{pH}$ values $<2$, while at a $\mathrm{pH}$ value of 3.6; half of 144 the molecules are dissociated (negatively charged) due to deprotonation of the carboxylic 145 group $(-\mathrm{COOH})$. As the $\mathrm{pH}$ raises beyond, the CGA molecule is more negative due to 146 deprotonation of the $\mathrm{OH}$ group from the catechol moiety $\left(-\mathrm{C}_{6} \mathrm{H}_{4}(\mathrm{OH})_{2}\right)$. A similar behavior 147 occurs for CA (Figure 1b).

\subsection{Quantification of CA and CGA}

150 The quantification of the individual concentration of CA and CGA in aqueous solution was 151 carried out by UV-Vis spectroscopy using a double-beam spectrophotometer (Shimadzu UV 
152 2600). The absorbance of a CGA solution was measured at $325 \mathrm{~nm}$ for the 3-7 $\mathrm{pH}$ range,

153 while 322 ( $\mathrm{pH}$ value of 3$)$ and $287 \mathrm{~nm}$ (5-7 of $\mathrm{pH}$ range) were used for CA. The quantification

154 of CA and CGA in binary solutions was carried out using and HPLC equipped with a DAD

155 (Agilent model 2998). A 10-min linear gradient was run after sample (or standard) injection

$156(10 \mu \mathrm{L})$ using solvents $\mathrm{A}(0.1 \%$ trifluoroacetic acid in water $)$ and $\mathrm{B}(0.1 \%$ trifluoroacetic acid

157 in acetonitrile). Detection was performed at $250 \mathrm{~nm}$ using a flowrate of $0.6 \mathrm{~mL} \mathrm{~min}{ }^{-1}$.

\subsection{Adsorbent}

160 A commercial F400 granular activated carbon (GAC) was used as adsorbent; it was a gift

161 from the Calgon Carbon Corp. Before using it, the GAC was sieved through a 30-50 mesh to 162 obtain particles with an average radius of $0.542 \mathrm{~mm}$, which were washed three times with 163 deionized water to eliminate dust and impurities. The GAC washed was afterwards dried at $164110^{\circ} \mathrm{C}$ for $24 \mathrm{~h}$ using a conventional model, the material was finally stored in a sealed 165 container. The textural properties of the adsorbent (specific surface area, pore volume, and 166 average pore diameter) were determined by $\mathrm{N}_{2}$ physisorption at $77 \mathrm{~K}$ using a Micromeritics 167 ASAP 2020 equipment. The superficial area $\left(\mathrm{S}_{\mathrm{BET}}\right)$ and micropores volume $\left(\mathrm{V}_{\text {mic }}\right)$ were 168 calculated using the models proposed by Brunauer, Emmett, and Teller (BET) and Dubinin169 Radushkevich, respectively. The diameter of the micropores $\left(\mathrm{L}_{0}\right)$ was estimated using the 170 equation proposed by Stoeckli (1995) (Stoeckli et al. 1995), while the superficial chemistry 171 was studied by the acid-base titration method proposed by Boehm (1994) (Boehm 1994). 172 Finally, the surface charge of the GAC was determined using the acid-base titration method 173 established by Kuzin and Loskutov (1996) (Kuzin, I. A. y Loskutov 1996). 
176 The concentration decay curves for CA and CGA on GAC were determined using a rotatory 177 basket batch adsorber. The mechanical details of this adsorber are reported elsewhere 178 (Ocampo-Perez et al. 2017). The procedure employed is briefly described. First, $0.5 \mathrm{~g}$ of 179 GAC were added to a basket, which was later anchored to the motor shaft. The stirring 180 velocity was set to $200 \mathrm{rpm}$ (higher velocities did not affect the adsorption velocity). 181 Afterwards, a $1 \mathrm{~L}$ solution was rapidly added having a known initial concentration of the 182 compounds studied. This initial concentration was varied for CA (0.57-2.27 mmol L-1) and 183 CGA $\left(0.29-1.69 \mathrm{mmol} \mathrm{L}^{-1}\right) .1 \mathrm{~mL}$ aliquots were withdrawn for the system at specified time 184 points to determine acid concentrations until reaching equilibrium. Temperature was kept at $18525^{\circ} \mathrm{C}$ during the whole experiment by keeping the system immersed in a water bath. To study 186 the effect of the adsorption $\mathrm{pH}$ on the adsorption capacity and velocity, experiments were 187 conducted at $\mathrm{pH}$ values of 3,5 , and 7 (by adding $0.01 \mathrm{M} \mathrm{HCl}$ or $0.01 \mathrm{M} \mathrm{NaOH}$ ). The mass 188 of CA or CGA adsorbed was determined at each time point using Equation 1, while the 189 equilibrium adsorption capacity was calculated using Equation 2.

190

$$
\begin{aligned}
& \mathrm{q}=\frac{\mathrm{V}\left(\mathrm{C}_{\mathrm{A} 0}-\mathrm{C}_{\mathrm{A}}(\mathrm{t})\right)}{\mathrm{m}} \\
& \mathrm{q}_{\mathrm{e}}=\frac{\mathrm{V}\left(\mathrm{C}_{\mathrm{A} 0}-\mathrm{C}_{\mathrm{Ae}}\right)}{\mathrm{m}}
\end{aligned}
$$




\subsection{Mathematical models}

195 Several mathematical models to interpret the adsorption velocity are available in the 196 literature. These models are based on some of the three stages of mass transport that exist 197 during the adsorption process (external mass transport, intraparticle diffusion, and adsorption 198 on the active site. Each of these stages represent a mass transfer resistance and, as usual, the 199 slowest stage will control the global adsorption velocity. The kinetic models consider that 200 the global adsorption velocity is controlled by the adsorption the active site, disregarding the 201 intraparticle diffusion and external mass transport. Moreover, the controlling stage is 202 represented by a reaction rate. The kinetic models most employed are the first order 203 (Lagergren equation) and second order models. Unlike the kinetic models, the diffusional 204 models are obtained from mass balances and constitutive equations (adsorption isotherm); 205 therefore, the mass transport parameters can be related with the operation variables.

\section{$207 \quad$ 2.5.1. First order kinetic model}

208 The first order kinetic model is described by Equation 3 (it is solved considering that at the 209 beginning of the adsorption process, no adsorbate exists on the particle). It considers that the 210 adsorption is driven by a linear driving force generated from the difference between the

211 equilibrium capacity and the existing capacity such that the process is interrupted when 212 reaching equilibrium.

$$
\frac{\mathrm{dq}}{\mathrm{dt}}=\mathrm{k}_{1}\left(\mathrm{q}_{\mathrm{e}}-\mathrm{q}\right)
$$




\subsubsection{Second order kinetic model}

214 The second order kinetic model is expressed in Equation 4. The same driving force of the 215 first order model is considered but squared to indicate a faster adsorption process. The same 216 initial condition of the first order model is used.

$$
\frac{\mathrm{dq}}{\mathrm{dt}}=\mathrm{k}_{2}\left(\mathrm{q}_{\mathrm{e}}-\mathrm{q}\right)^{2}
$$

217

218

\subsubsection{Intraparticle diffusion model}

To evaluate the existence of diffusional phenomena during the adsorption process, the intraparticle diffusion equation is widely used in the literature. This model indicates that the adsorption capacity varies linearly with $\mathrm{t}^{0.5}$. If the data show good linearity a pass through the origin, it can be stated that the adsorption rate is controlled by intraparticle diffusion $[49,50]$. Moreover, different slopes during the adsorption process establish the presence of several mass transfer resistances. The intraparticle diffusion model is presented in Equation 5.

$$
\mathrm{q}_{\mathrm{t}}=\mathrm{k}_{\mathrm{i}} \mathrm{t}^{0.5}+\mathrm{b}
$$

\subsubsection{General diffusion model}

The general diffusion model (PVSDM) used in this work is based on the following considerations: i) the external mass transport is described by the film theory characterized by an external mass transfer coefficient, $\mathrm{k}_{\mathrm{L}}$, ii) intraparticle diffusion occurs by diffusion in the pore volume (Fickian diffusion) and surface diffusion, iii) the adsorption velocity on the active site is instantaneous, and iv) the GAC particles are spherical, rigid, and isotropic. From 
these considerations, mass balances of the adsorbate in the bulk solution and within the

234 particle establish Equations 6-9.

235

$$
\begin{gathered}
\mathrm{V} \frac{\mathrm{dC}}{\mathrm{dt}}=-\mathrm{mSk}_{\mathrm{L}}\left(\mathrm{C}_{\mathrm{A}}-\left.\mathrm{C}_{\mathrm{AP}}\right|_{\mathrm{B}_{\mathrm{p}-\mathrm{s}}}\right) \\
\varepsilon_{\mathrm{p}} \frac{\partial \mathrm{C}_{\mathrm{AP}}}{\partial \mathrm{t}}+\rho_{\mathrm{p}} \frac{\partial \mathrm{q}}{\partial \mathrm{t}}=\nabla \cdot\left(\mathrm{D}_{\mathrm{ep}} \nabla \mathrm{C}_{\mathrm{AP}}+\mathrm{D}_{\mathrm{s}} \rho_{\mathrm{p}} \nabla \mathrm{q}\right) \\
\mathrm{t}=0 \quad \mathrm{C}_{\mathrm{A}}=\mathrm{C}_{\mathrm{A} 0} \quad \mathrm{C}_{\mathrm{AP}}=0 \\
-\mathbf{n}_{\mathrm{p}-\mathrm{s}} \cdot\left(\mathrm{D}_{\mathrm{ep}} \nabla \mathrm{C}_{\mathrm{AP}}+\mathrm{D}_{\mathrm{s}} \rho_{\mathrm{p}} \nabla \mathrm{q}\right)=\mathrm{k}_{\mathrm{L}}\left(\mathrm{C}_{\mathrm{A}}-\left.\mathrm{C}_{\mathrm{AP}}\right|_{\mathrm{B}_{\mathrm{p}-\mathrm{s}}}\right)
\end{gathered}
$$

236

237

238

239

240

241

242

243

244 of the particle $(r=R)$.

245

246 247 solution $\left(\mathrm{C}_{\mathrm{AP}}=\mathrm{C}_{\mathrm{Ae}}\right)$ and the mass of solute adsorbed on the pore surface. This equilibrium 248 is represented by the adsorption isotherm, which is the mathematical relationship between $\mathrm{q}$ 249 and $\mathrm{C}_{\mathrm{AP}}$ (Equation 10).

Equation 6 represents the variation of solute concentration in the solution due to the transport of solute from the solution to the external surface of the particle. The left-hand side of Equation 7 indicates that the solute inside the particle accumulates in the volume and surface of the pores. Meanwhile, the right-hand side indicates that the intraparticle diffusion of the solute can occur by diffusion in the pore volume and surface diffusion. The initial and boundary conditions (Equations 8-9) indicate that at the beginning $(\mathrm{t}=0)$ there is no solute inside the pores of the particle, and there is continuity of the mass flux at the external surface Usually, the adsorption rate on an active site is assumed to be instantaneous; therefore, local equilibrium exists between the concentration of solute in the solution inside the pore

$$
q=f\left(C_{A P}\right)
$$


251 2.6. Binary adsorption of CA and CGA on GAC

252 The experimental data of binary adsorption at equilibrium were obtained using a batch

253 adsorber. This adsorber consists in a $50 \mathrm{~mL}$ centrifuge tube that contains the binary solution

254 of known concentration and certain adsorbent mass, the tube is immersed in a constant-

255 temperature (by a circulating fluid) water bath. The procedures to obtain data was as follows:

$2560.05 \mathrm{~g}$ of GAC were added to the tube along with the binary solution of initial concentration

257 (varied from 0.29 to $1.69 \mathrm{mmol} \mathrm{L}^{-1}$ for $\mathrm{CA}$ and CGA). The initial $\mathrm{pH}$ value was set to 3 ; it

258 was maintained by adding $0.1 \mathrm{~N} \mathrm{HCl}$ throughout the experiment. The system was allowed to

259 reach equilibrium and a $1 \mathrm{~mL}$ sample was withdrawn to determine concentration of both

260 acids. Finally, the adsorption capacity of GAC towards each acid was evaluated using

261 Equation 2.

262

263

\section{RESULTS AND DISCUSSION}

\section{3.1 Textural and chemical properties of GAC}

265 The chemical properties of GAC were obtained using an acid-base titration. The

266 concentration of total acid sites was $0.090 \mathrm{meq} / \mathrm{g}$, while that for total basic sites was 0.486

$267 \mathrm{meq} / \mathrm{g}$. Therefore, the surface of GAC has a predominantly basic character. The pH value of

268 zero charge, $\mathrm{pH}$ PzC, resulted equal to 9.4, which indicates that $\mathrm{pH}$ values below 9.4 propitiate

269 a positively charged GAC surface, while the opposite (negatively charged) occurs at $\mathrm{pH}$

270 values above 9.4. This result also corroborates the basic character of the GAC surface.

The textural properties were obtained from the experimental data of the adsorption-

272 desorption isotherm of $\mathrm{N}_{2}$ at $77 \mathrm{~K}$ (Figure 2). In this isotherm, a type I-B behavior is observed, 
273 which is characteristic of microporous materials (a great amount of $\mathrm{N}_{2}$ is adsorbed at low

274 pressures). Moreover, a slight type H4 hysteresis loop can be observed, which is

275 representative of solids with pores with narrow slit. The experimental data heled determining

276 that the total pore volume for the material studied was $0.36 \mathrm{~cm}^{3} \mathrm{~g}^{-1}$ (for a $\mathrm{P} / \mathrm{P}_{0}$ value of 0.95 ),

277 which confirms that the porosity of the material is adequate. The BET equation established

278 a specific area of $686 \mathrm{~m}^{2} \mathrm{~g}^{-1}$, while the microporous area was $443 \mathrm{~m}^{2} \mathrm{~g}^{-1}$ with a micropore

279 volume of $0.32 \mathrm{~cm}^{3} \mathrm{~g}^{-1}$ (both determined using the Dubinin-Radushkevich equation). Finally,

280 the pore size distribution presented in Figure 2 was obtained by the DFT method, a narrow

281 unimodal distribution is observed with a slight presence of 2-30 $\mathrm{nm}$ mesopores.

\subsection{Individual and binary adsorption at equilibrium}

284 The adsorption equilibrium for both acids was studied at $\mathrm{pH}$ values of 3,5 , and 7 (at $25^{\circ} \mathrm{C}$ ), at these $\mathrm{pH}$ values studied the adsorption capacity is expected to be affected through changes not only in the surface charge of the adsorbent but the speciation of the acids studied. Additionally, experiments at $\mathrm{pH}$ values above 7 were not carried out due to stability issues of both acids (Mendel Friedman and Hella S. Jurgens 2000). For the adsorption process of

289 CA, Figure 3a shows that the adsorption isotherms have a similar behavior (type I isotherm) 290 with a marked asymptotic tendency when increasing the equilibrium concentration 291 irrespective of the $\mathrm{pH}$ value. This phenomenon might be attributed to the generation of a 292 monolayer on the surface of the adsorbent during the adsorption process. This implies a non293 existent interaction between the CA molecules adsorbed. Moreover, once an adsorption site 294 is occupied by a molecule, it is not possible for another molecule to become adsorbed 295 inhibiting a multilayer adsorption. This suggests that one of the adsorption mechanisms 
296 involved are $\pi-\pi$ interactions between the aromatic ring of the CA molecule and the graphitic 297 planes of GAC.

The adsorption capacity obtained at different $\mathrm{pH}$ values revealed that increasing the $\mathrm{pH}$ value of the solution improved the adsorption process. In this regard, at an equilibrium concentration of $1.2 \mathrm{mmol} \mathrm{L}-1$ the adsorption capacity increased by $15 \%$ when the $\mathrm{pH}$ value raised from 3 to 5. Similarly, a 50\% increase was obtained when the $\mathrm{pH}$ values changes from in $\mathrm{pH}$ promotes the dissociation of $\mathrm{CA}$ generating negatively charged species at $\mathrm{pH}>6$. This situation promotes the establishment of attractive electrostatic interactions (combined with the $\pi-\pi$ interactions) between CA and the surface of the adsorbent; therefore, increasing the adsorption capacity in response to the increase in $\mathrm{pH}$ value of the solution.

For the case of CGA adsorption, a slightly different behavior is obtained when compared to GA at the $\mathrm{pH}$ values studied. Moreover, the adsorption isotherms showed an non-asymptotic behavior upon increasing the equilibrium concentration. In general, the

311 adsorption capacity of CGA at $\mathrm{pH}$ values of 3 and 5 resulted similar to those obtained for $312 \mathrm{CA}$, while an increase of only $15 \%$ was observed at $\mathrm{pH} 7$. These results imply that despite 313 the existence of electrostatic interactions at $\mathrm{pH} 7$; they do not have the same adsorption force 314 determined for the case of CA. This situation might be attributed to the nonplanar structure 315 of CGA when compared to CA (Figure 4), which ends up affecting the $\pi-\pi$ interaction. 316 Therefore, the electrostatic forces have influence on the adsorption over the positively 317 charged adsorbent surface; nonetheless, they are not synergistic with the $\pi-\pi$ interactions to 318 the same level found with CA, promoting less surface saturation. 
320 Freundlich and Langmuir isotherm models represented by Equations 11 and 12, respectively.

321 The optimized values of the fitting parameters were determined using nonlinear regression 322 using Statistica ${ }^{\circledR}$, Table 2 shows the results for each model. The $\mathrm{R}^{2}$ values establish that the 323 Langmuir model better represents the adsorption of CA given the asymptotic behavior of the 324 data, while the Freundlich model better describes the data for CGA (Figure 3b).

$$
\begin{aligned}
\mathrm{q}_{\mathrm{e}} & =\frac{\mathrm{q}_{\mathrm{m}} \mathrm{KC}_{\mathrm{e}}}{1+\mathrm{KC}_{\mathrm{e}}} \\
\mathrm{q}_{\mathrm{e}} & =\mathrm{kC}_{\mathrm{e}}^{1 / \mathrm{n}}
\end{aligned}
$$

Figure 5 shows the experimental data for the adsorption equilibrium of the binary 326 solution of $\mathrm{CA}$ and $\mathrm{CGA}$ on $\mathrm{GAC}$ at $25^{\circ} \mathrm{C}$ and $\mathrm{pH}$ set to 3 . This $\mathrm{pH}$ value was selected 327 considering that the residual water from the coffee production process has similar $\mathrm{pH}$ value 328 (Haddis and Devi 2008; Selvamurugan et al. 2010; Alemayehu et al. 2020). The experimental 329 data for the binary system was interpreted by the extended multicomponent Langmuir (EML) 330 model, which is described in Equation 13.

$$
\mathrm{q}_{\mathrm{i}}=\frac{\mathrm{q}_{\max } \mathrm{K}_{\mathrm{E}, \mathrm{i}} \mathrm{C}_{\mathrm{i}}}{1+\sum_{\mathrm{j}=1}^{\mathrm{N}} \mathrm{K}_{\mathrm{E}, \mathrm{j}} \mathrm{C}_{\mathrm{i}}}
$$

The EML model assumes that the adsorption sites on the adsorbent surface are uniform; therefore, both adsorbates compete for the same adsorption sites that are 333 energetically equal. Table 3 shows the values of the optimized parameters from the model, $334 \mathrm{q}_{\max }$ reaches a value of $1.48 \mathrm{mmol} \mathrm{g}^{-1}$, while the values of $\mathrm{K}_{\mathrm{EI}}$ demonstrate that the GAC 335 surface has higher (almost 2-fold) affinity towards CGA when compared to CA. The 

355 sites.

prediction of the EML model is presented in Figure 3 for both compounds where good fitting to the experimental data is observed.

The effect of CGA presence on the adsorption capacity of CA is presented in Figure 5a. In this figure, the adsorption capacity of CA is drastically reduced at CGA equilibrium concentrations less than 0.2 meq $\mathrm{L}^{-1}$, whereas at higher concentrations the effect is less evident. To clarify this even further, Figure $5 \mathrm{~b}$ presents the mass of CA adsorbed as a function of the CGA equilibrium concentration; here, the effect described is mor evident. Furthermore, at a CGA equilibrium concentration of $1 \mathrm{mmol} \mathrm{L}^{-1}$, the adsorption capacity diminishes by $73 \%$, which clearly indicates the preference of the GAC surface for CGA at higher equilibrium concentrations of the same.

Figures 5c and 5d show the effect of the CA presence on the CGA adsorption, it can be appreciated that the adsorption capacity diminishes in a less pronounced fashion when compared to the results obtained for the adsorption of CA. As an example, for equilibrium concentrations of 1 and $0.7 \mathrm{mmol} \mathrm{L}^{-1}$ for $\mathrm{CA}$ and CGA, respectively, the adsorption capacity decreases by $40 \%$ corroborating the preference of GAC for CGA. The XLogP3 values for CA and CGA are 1.2 and -0.4 ; therefore, the latter has a more hydrophobic character, which favors its adsorption when competing with the former. Finally, the maximum value found for $\mathrm{q}_{\mathrm{m}}$ in the binary system lies in the range estimated for the individual system, i.e. the binary adsorption of CA and CGA is antagonistic since both acids adsorb on the same adsorption

\subsection{Adsorption rate of CA and CGA on GAC}

357 Tables 4 and 5 show the operating conditions employed to obtain the adsorption kinetics for 358 both individual acids on GAC, while Figure 6a-b shows as an example the experimental data 
for CA (Exp. 1-4) and CGA (Exp. 1-5), respectively. For both acids, the adsorption capacity rapidly increases for the first 200 and $1000 \mathrm{~min}$, respectively. Afterwards, the adsorption capacity slowly increases until reaching equilibrium. This behavior implies the existence of diverse mass transfer resistances during the adsorption process associated to the microporous character of the adsorbent. The equilibrium conditions were reached at approximately 1,800 and 10,000 min for CA and CGA, respectively, i.e. the adsorption rate of CA is $\sim 5$ times faster than for CGA. These results could be explained in terms of the molecular size of CGA (Table 1) that is $\sim 2$ times larger than the size of CA, which could render a slower diffusion process within the microporosity of the adsorbent for the former. Another factor to consider is the structure of the adsorbent that presents an average pore diameter of $1.21 \mathrm{~nm}$; this value is close to the molecular size of CGA. Therefore, for CGA restrictive diffusional effects might exist hindering the adsorption process. Moreover, the behavior observed for CGA might also be attributed to steric effects derived from the number and position of the hydroxyl moieties in the aromatic ring (Li et al. 2010; Simanaviciute et al. 2017); this situation could induce that the adsorbed molecules restrict the diffusion of new CGA molecules, which results in a more complex adsorption mechanism with the subsequent longer equilibration times.

\subsection{Interpretation of the experimental data for the adsorption rate of CA and CGA on} GAC using kinetic models

The experimental data for CA and CGA were interpreted by the pseudo-first and pseudosecond order kinetic models (Equations 3 and 4), respectively. The optimized values for the parameters $\mathrm{k}_{1}, \mathrm{k}_{2}$, qeexp1, and qeexp2 were obtained by nonlinear fitting using Scientist $\mathrm{q}_{\text {, the }}$ results are shown in Tables 4 and 5 for CA and CGA, respectively. Both kinetic models 
appropriately describe the experimental data according to the values obtained for the correlation coefficient $\left(\mathrm{R}^{2}\right)$; nonetheless, the pseudo-second order model shows $\mathrm{R}^{2}$ values closer to 1 and values of $\mathrm{q}_{\mathrm{e}}$ closer to the experimental data. Therefore, this model was selected to describe the adsorption process of both compounds (See Figure 6a-b). As mentioned before, the kinetic models consider that the adsorption rate is governed by the surface reaction neglecting the external mass transport and intraparticle diffusion. In this sense, to evaluate the existence of a correlation between $\mathrm{k}_{2}$ and the operating conditions, Figure 7 shows the variation of $\mathrm{k}_{2}$ as a function of $\mathrm{q}_{\mathrm{e}}$ at the different $\mathrm{pH}$ values studied. For the case of $\mathrm{CA}, \mathrm{k}_{2}$ did not present a tendency when increasing qe or modifying the solution $\mathrm{pH}$, which could indicate the likely presence of other mass transfer resistances. On the other hand, for CGA the value of $\mathrm{k}_{2}$ diminishes exponentially upon increasing the value of $\mathrm{q}_{\mathrm{e}}$; this could be ascribed to the availability of active sites on the adsorbent surface, which are reduced as the adsorption process progresses.

Figure $8 \mathrm{a}-\mathrm{b}$ presents as an example, the analysis of the experimental data interpreted by the intraparticle diffusion model (Equation 5) for CA (Exp. 1-4) and CGA (Exp. 1-5) correspondingly, while Tables 6 and 7 show the values for the intraparticle diffusion rate constant $\left(\mathrm{k}_{\mathrm{i}}\right)$, regression coefficient $\left(\mathrm{R}^{2}\right)$, and y-intercept (b) for all experiments. Considering the values of the regression coefficient, the intraparticle diffusion model properly describes the experimental data for both acids. Furthermore, the graphs (Figure 8) showed multilinearity, which indicates the presence of several mass transfer resistances. For CA and CGA, the values of $\mathrm{k}_{\mathrm{i}}$ were compared in three sections. Based on this, it can be inferred that at the beginning (section 1) of the adsorption process the external mass transfer is important given that this section shows higher values of $k_{i}$ for both acids. Section 2 defines the point where 
the adsorption velocity starts to be controlled by the intraparticle diffusion. In this case, the

406 values for ki are slightly higher for CA when compared to CGA, which could be associated

407 to the complexity of the CGA molecule (bigger size and number of hydroxyl moieties) that

408 could render a higher resistance to diffusion.

\section{3.5. Experimental data interpretation by the diffusional model}

410 The previous section established that several mass transfer resistances exist during the

411 adsorption of both acids. For this reason, the PVSDM was used to interpret the experimental

412 data. This model considers that the intraparticle diffusion occurs simultaneously in the pore

413 volume and on the surface. To solve this model, it is necessary to calculate the values for the

414 external mass transport coefficient $\left(\mathrm{k}_{\mathrm{L}}\right)$, effective diffusion coefficient $\left(\mathrm{D}_{\mathrm{ep}}\right)$, and superficial

415 diffusion coefficient $\left(D_{s}\right)$.

The values for $\mathrm{kL}_{\mathrm{L}}$ were estimated using Equation 14, which was developed by

417 Furusawa and Smith (1973) (Furusawa and Smith 1973) for stirred tank reactors.

$$
\mathrm{k}_{\mathrm{L}}=-\frac{\mathrm{V}}{\mathrm{mS}}\left[\frac{\mathrm{d}\left(\frac{\mathrm{C}_{\mathrm{A}}}{\mathrm{C}_{\mathrm{A} 0}}\right)}{\mathrm{dt}}\right]_{\mathrm{t} \rightarrow 0}
$$

419 In Equation 14, the term in square brackets is the slope of the kinetic curve at time

420 closer to zero. The values of $\mathrm{k}_{\mathrm{L}}$ obtained for both acids are presented in Tables 8 and 9 with

421 higher values for CA when compared to CGA, which indicates higher external mass transfer 422 of CA towards the surface of GAC. These results are in line with those obtained with the 423 intraparticle diffusion model from the previous section. 
425 GAC studied of 3.5 [54].

$$
\mathrm{D}_{\mathrm{ep}}=\frac{\mathrm{D}_{\mathrm{AB}} \varepsilon_{\mathrm{P}}}{\tau}
$$

426

427

428

429 430

431

432

Substituting the values for $\mathrm{D}_{\mathrm{AB}}$, in Equation 15, reported in Table 1 and considering $\varepsilon_{\mathrm{p}}=0.554$, values of $\mathrm{D}_{\text {ep }}$ equal to $1.19 \times 10^{-6}$ and $7.84 \times 10^{-7} \mathrm{~cm}^{2} \mathrm{~s}^{-1}$ were obtained for $\mathrm{CA}$ and CGA, respectively.

Finally, the value of $\mathrm{D}_{\mathrm{s}}$ was obtained by fitting the PVSDM model to the experimental data using Equation 16 as objective function.

$$
\text { Error }=\int_{0}^{t}\left(C_{A, \exp }-C_{A, p r e d}\right)^{2} d t
$$

As an example, Figure 9 shows the experimental data for Exp. 2 for CA and Exp. 4 for CGA along with the prediction of the PVSDM model using the optimized values for $\mathrm{D}_{\mathrm{s}}$ of $5.04 \times 10^{-9}$ and $3.89 \times 10^{-10} \mathrm{~cm}^{2} \mathrm{~s}^{-1}$ for CA and CGA, respectively. For both cases, the model successfully describes the experimental data during the whole experiment. This methodology was replicated for all the experiments and the optimum values for $\mathrm{D}_{\mathrm{s}}$ are compiled in Tables 8 and 9 for CA and CGA, respectively. When comparing the values for $\mathrm{D}_{\mathrm{s}}$ for $\mathrm{CA}$ and CGA, the values for the former are higher than for the latter, which helps explaining the longer diffusion times for CGA.

Figures 10a and 10b show the evolution of concentration profiles within the adsorbent particle for CA (experiment 2) and CGA (experiment 4), respectively. In general, the concentration profiles are symmetrical due to the isotropy condition assumed during the 
mathematical formulation and the fact the concentration gradients are higher in the external

443 surface of the adsorbent at any moment. Additionally, the direction of the concentration

444 gradient always points towards the center of the adsorbent particle since at this point the

445 concentration is always smaller, if the equilibrium is not reached. Finally, as time progresses

446 the saturation of the material increases from the outside to the inside of the particle. Similar

447 results were obtained for the rest of the experiments for both acids (data not shown).

448

449

450

451

452

453

454 and time for CA and CGA, respectively. The timepoints selected for analysis were 5, 10, and

$45720 \mathrm{~h}$ for CA and 17,42 , and $84 \mathrm{~h}$ for CGA. It is worth mentioning that the minimum values

$$
\mathbf{N}_{\mathrm{AS}}=-\mathrm{D}_{\mathrm{s}} \rho_{\mathrm{p}} \nabla \mathrm{q}
$$

$$
\mathbf{N}_{\mathrm{AS}}=\mathrm{D}_{\mathrm{s}} \rho_{\mathrm{p}} \sqrt{\left(\left.\nabla \mathrm{q}\right|_{\mathrm{r}}\right)^{2}+\left(\left.\nabla \mathrm{q}\right|_{\theta}\right)^{2}+\left(\left.\nabla \mathrm{q}\right|_{\varphi}\right)^{2}}
$$

Figures 11a and 11b show the surface diffusion contribution as a function of position 
for $\% \mathrm{SDC}$ were 55.9 and $25.5 \%$ for $\mathrm{CA}$ and $\mathrm{CGA}$, respectively; they were found at the beginning of the adsorption process. These values further increased as the adsorption progressed reaching values of $100 \%$ at longer timepoints. These results suggest that, for both acids, both diffusion mechanisms must be considered for the scaling-up of the process. Similar analyses were performed for experiments 1-12 for CA and 1-14 for CGA, the optimized values for $\mathrm{D}_{\mathrm{s}}$ are summarized in Tables 8 and 9 , respectively. In general, it is notable that the values of $\mathrm{D}_{\mathrm{s}}$ for CGA are one order of magnitude smaller than those for CA, which further evidenced restricted diffusional effects for CGA mainly associated to its bigger molecular size. Moreover, the values of $\mathrm{D}_{\mathrm{s}}$ did not show any tendency with respect to the $\mathrm{pH}$ value or the mass adsorbed at equilibrium $\left(\mathrm{q}_{\mathrm{e}}\right)$. Finally, Figure 12 shows the prediction of the PVSDM model along with the experimental data where the model satisfactorily predicts the dynamics of the adsorption process irrespective of the operating conditions of the system.

\section{CONCLUSIONS}

In this work, the single and binary adsorption of CA and CGA on GAC were studied. A profound study of the mass transfer mechanisms during the adsorption of both acids was also performed. The adsorption experiments of the individual compounds demonstrated that GAC has high affinity towards them reaching maximum adsorption capacities of 1.33 and 1.62 mmol $\mathrm{g}^{-1}$ for CA and CGA, respectively. The mechanism involved during the adsorption of both acids was mainly attributed to $\pi-\pi$ and electrostatic interactions at the $\mathrm{pH}$ values studied.

The binary adsorption demonstrated that the presence of CA or CGA during the adsorption of CGA or CA, respectively, detriments the adsorption capacity with a more pronounce effect for CA. Moreover, the results revealed that the adsorption of both compounds is antagonistic given their similarity in adsorption mechanisms. 
482 that the pseudo-second order model provided better description of the data when compared

483 to the pseudo-first order model. Moreover, the value of the kinetic constant diminishes as the

484 adsorbed amount in the equilibrium increases due to a reduction in the availability of active

485 sites. The intraparticle diffusion model corroborated the presence of several mass transfer

486 resistance during the adsorption of both acids.

487 Finally, the interpretation of the experimental data with diffusional models helped 488 establishing that the adsorption rate of both acids is governed by intraparticle diffusion, and 489 that superficial diffusion and pore volume diffusion play important roles during adsorption 490 of both compounds. 


\section{Declarations}

493

494

495

496

497

498

499

500

501

502

503

504

505

506

507

508

509

510

511

512

513

Ethical approval: Not applicable.

Consent to participate: Not applicable.

Consent for publication: Not applicable.

\section{Availability of data and materials' statement}

The datasets used and/or analysed during the current study are available from the corresponding author on reasonable request

\section{Declaration of Competing Interest}

The authors declare that they have no known competing financial interests that could have influence the work reported in this paper.

\section{Authors' contributions}

Conceptualization, R.O.-P. and E.P.-O.; methodology and experimental E.E.H-P; validation, A.I.Z.-G., O.G.-O., A.G.-D., P.D.-S., and F.B.-C; formal analysis, A.I.Z-G. and R.O.-P.; investigation, R.O.-P.; writing — original draft preparation, A.I.Z.-G. and R.O.-P.; writingreview and editing, R.O.-P., A.I.Z.-G and E. P.-O. All authors read and approved the final manuscript. 


\section{Acknowledgements}

516 This work was funded by Consejo Nacional de Ciencia y Tecnología (National Council for

517 Science and Technology), CONACyT, Mexico, through Grant No. 1006615.

518 Dra. Ana I. Zárate-Guzmán thanks Consejo Nacional de Ciencia y Tecnología

519 (National Council of Science and Technology), CONACYT, Mexico, for the support 520 received through the "Convocatoria 2020: Estancias posdoctorales por México". 


\section{References}

524 Alemayehu YA, Asfaw SL, Tirfie TA (2020) Management options for coffee processing

525 wastewater. A review. J Mater Cycles Waste Manag 22:454-469.

526 https://doi.org/10.1007/s10163-019-00953-y

527 Boehm HP (1994) Some aspects of the surface chemistry of carbon blacks and other

528 carbons. Carbon N Y 32:759-769. https://doi.org/10.1016/0008-6223(94)90031-0

529 Carrales-Alvarado DH, Leyva-Ramos R, Martínez-Costa JI, Ocampo-Pérez R (2018)

530 Competitive Adsorption of Dimetridazole and Metronidazole Antibiotics on Carbon

$531 \quad$ Materials from Aqueous Solution. Water Air Soil Pollut 229:.

532 https://doi.org/10.1007/s11270-018-3730-4

533 Chang WC, Hsieh CH, Hsiao MW, et al (2010) Caffeic Acid Induces Apoptosis in Human

534 Cervical Cancer Cells Through the Mitochondrial Pathway. Taiwan J Obstet Gynecol 535 49:419-424. https://doi.org/10.1016/S1028-4559(10)60092-7

536 Du N, Cao S, Yu Y (2011) Research on the adsorption property of supported ionic liquids

537 for ferulic acid, caffeic acid and salicylic acid. J Chromatogr B Anal Technol Biomed

$538 \quad$ Life Sci 879:1697-1703. https://doi.org/10.1016/j.jchromb.2011.04.013

539 Farah A, Donangelo CM (2006) Phenolic compounds in coffee. Brazilian J Plant Physiol

$540 \quad$ 18:23-36. https://doi.org/10.1590/S1677-04202006000100003

541 Furusawa T, Smith JM (1973) Fluid-Particle and Intraparticle Mass Transport Rates in 542 Slurries. Ind Eng Chem Fundam 12:197-203. https://doi.org/10.1021/1160046a009 
543

544

545

546

547

548

549

550

551

552

553

554

555

556

557

558

559

560

561

562

563

Haddis A, Devi R (2008) Effect of effluent generated from coffee processing plant on the water bodies and human health in its vicinity. J Hazard Mater 152:259-262. https://doi.org/10.1016/j.jhazmat.2007.06.094

J.E. Braham and R. Bressani (1970) Pulpa de Café: Composición, tecnología y utilización

Jiang H, Li J, Chen L, Wang Z (2020) Adsorption and desorption of chlorogenic acid by macroporous adsorbent resins during extraction of Eucommia ulmoides leaves. Ind Crops Prod 149:112336. https://doi.org/10.1016/j.indcrop.2020.112336

Kuzin, I. A. y Loskutov AI (1996) No Title. J Appl chemestry

Li S, Huang K, Zhong M, et al (2010) Comparative studies on the interaction of caffeic acid, chlorogenic acid and ferulic acid with bovine serum albumin. Spectrochim Acta Part A Mol Biomol Spectrosc 77:680-686. https://doi.org/10.1016/j.saa.2010.04.026

Liudvinaviciute D, Rutkaite R, Bendoraitiene J, et al (2020) Adsorption of caffeic acid on chitosan powder. Polym Bull 78:2139-2154. https://doi.org/10.1007/s00289-020$03205-4$

Mendel Friedman and Hella S. Jurgens (2000) Effect of pH on the Stability of Plant Phenolic Compounds. J Agric Food Chem 2101-2110. https://doi.org/10.11777/j.issn1000-3304.2017.17064

Moritz M, Geszke-Moritz M (2016) Amine-modified SBA-15 and MCF mesoporous molecular sieves as promising sorbents for natural antioxidant. Modeling of caffeic acid adsorption. Mater Sci Eng C 61:411-421. https://doi.org/10.1016/j.msec.2015.12.093 
564 Mota FL, Queimada AJ, Pinho SP, Macedo EA (2008) Aqueous solubility of some natural

565 phenolic compounds. Ind Eng Chem Res 47:5182-5189.

566 https://doi.org/10.1021/ie071452o

567 Ocampo-Perez R, Aguilar-Madera CG, Díaz-Blancas V (2017) 3D modeling of overall

568 adsorption rate of acetaminophen on activated carbon pellets. Chem Eng J 321:510-

$569 \quad$ 520. https://doi.org/10.1016/j.cej.2017.03.137

570 Pettersen EF, Goddard TD, Huang CC, et al (2004) UCSF Chimera - A visualization

$571 \quad$ system for exploratory research and analysis. J Comput Chem 25:1605-1612.

572 https://doi.org/10.1002/jcc.20084

573 Selvamurugan M, Doraisamy P, Maheswari M (2010) An integrated treatment system for

$574 \quad$ coffee processing wastewater using anaerobic and aerobic process. Ecol Eng 36:1686-

575 1690. https://doi.org/10.1016/j.ecoleng.2010.07.013

576 Simanaviciute D, Klimaviciute R, Rutkaite R (2017) Equilibrium adsorption of caffeic,

577 chlorogenic and rosmarinic acids on cationic cross-linked starch with quaternary

578 ammonium groups. Int J Biol Macromol 95:788-795.

$579 \quad$ https://doi.org/10.1016/j.ijbiomac.2016.12.006

580 Singleton VL, Cilliers JJL (1991) Characterization of the Products of Nonenzymic

581 Autoxidative Phenolic Reactions in a Caffeic Acid Model System. J Agric Food Chem

$582 \quad 39: 1298-1303$. https://doi.org/10.1021/jf00007a021

583 Srivastava VC, Mall ID, Mishra IM (2006) Equilibrium modelling of single and binary

584 adsorption of cadmium and nickel onto bagasse fly ash. Chem Eng J 117:79-91.

$585 \quad$ https://doi.org/10.1016/j.cej.2005.11.021 
586 Stoeckli F, Centeno TA, Donnet JB, et al (1995) Characterization of industrial activated 587 carbons by adsorption and immersion techniques and by STM. Fuel 74:1582-1588. $588 \quad$ https://doi.org/10.1016/0016-2361(95)00168-5

589 Uranga JG, Podio NS, Wunderlin DA, Santiago AN (2016) Theoretical and Experimental 590 Study of the Antioxidant Behaviors of 5-O-Caffeoylquinic, Quinic and Caffeic Acids $591 \quad$ Based on Electronic and Structural Properties. ChemistrySelect 1:4113-4120. $592 \quad$ https://doi.org/10.1002/slct.201600582

593 Wang Y, Ho CT (2009) Polyphenols chemistry of tea and coffee: A century of progress. J $594 \quad$ Agric Food Chem 57:8109-8114. https://doi.org/10.1021/jf804025c

595

596

597

598

599

600

601

602

603

604

605 
a)

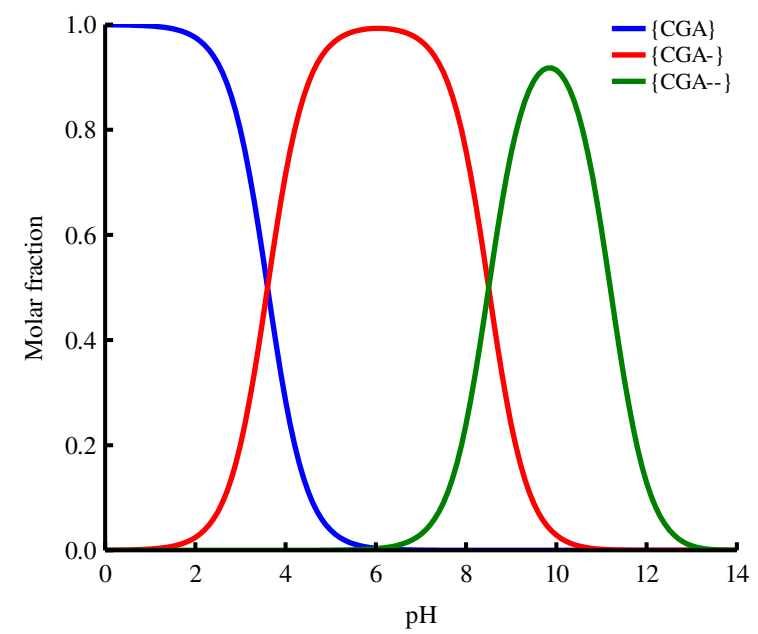

b)

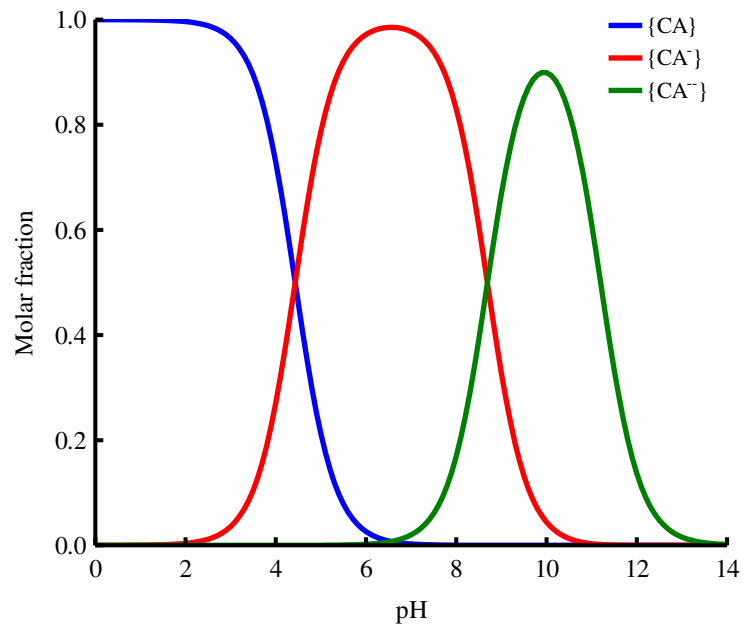

Figure 1. Speciation diagram of a) CGA and b) CA.

607

608

609

610

611

612

613

614

615

616

617

618

619

620

621 


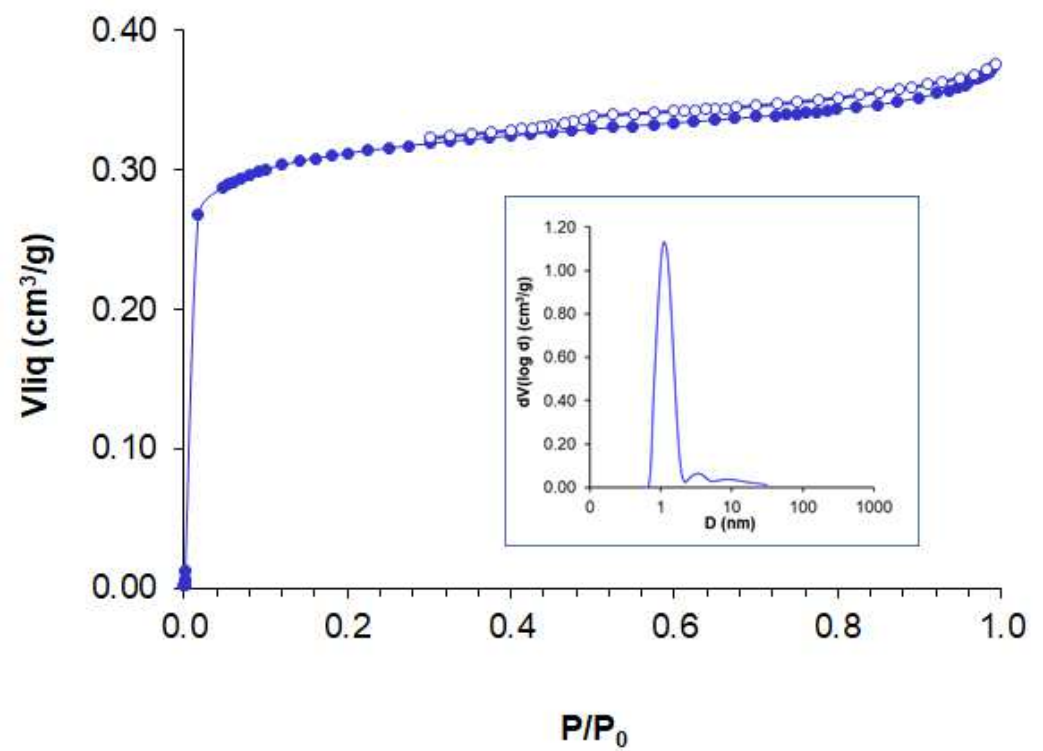

623

624 Figure 2. Adsorption-desorption isotherm of $\mathrm{N}_{2}$ at $77 \mathrm{~K}$ and pore size distribution.

625

626

627

628

629

630

631

632

633

634

635 
a)

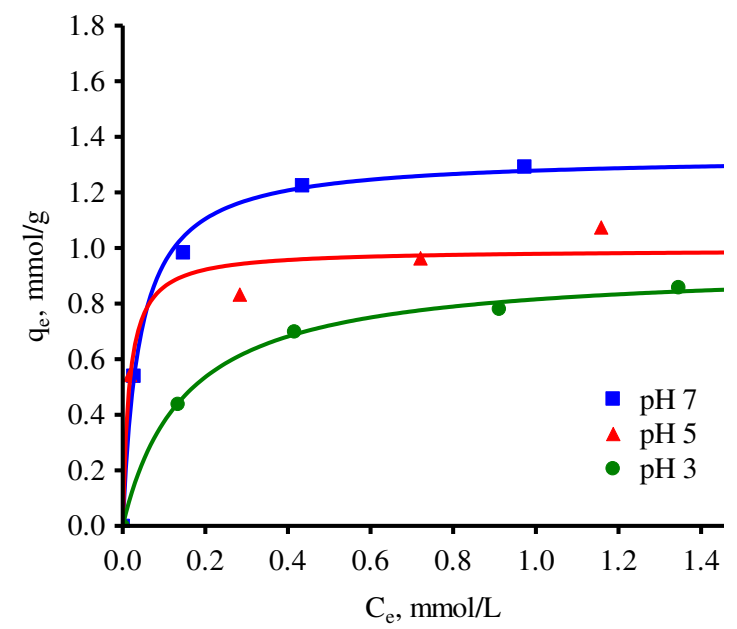

b)

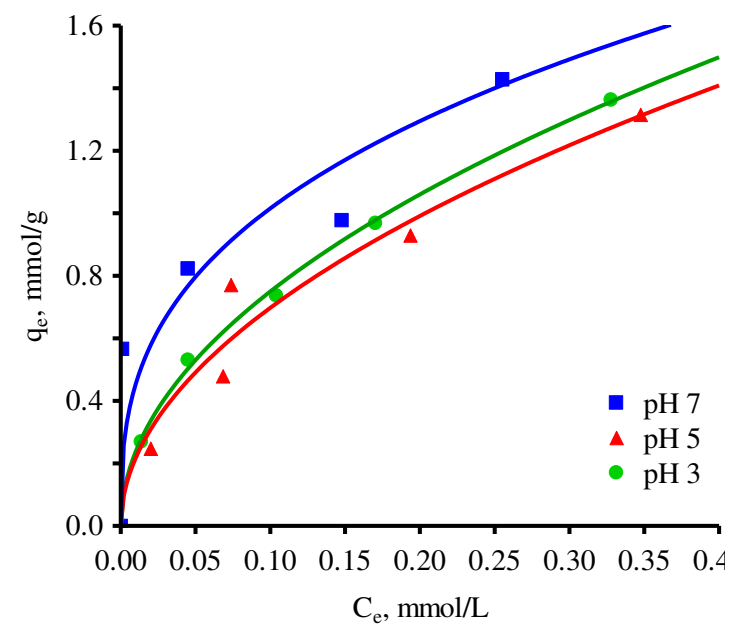

636 Figure 3. Adsorption isotherms for a) CA and b) CGA on GAC. The lines represent the

637 prediction of the Langmuir model for CA and Freundlich for CGA.

638

639

640

641

642

643

644

645

646

647 


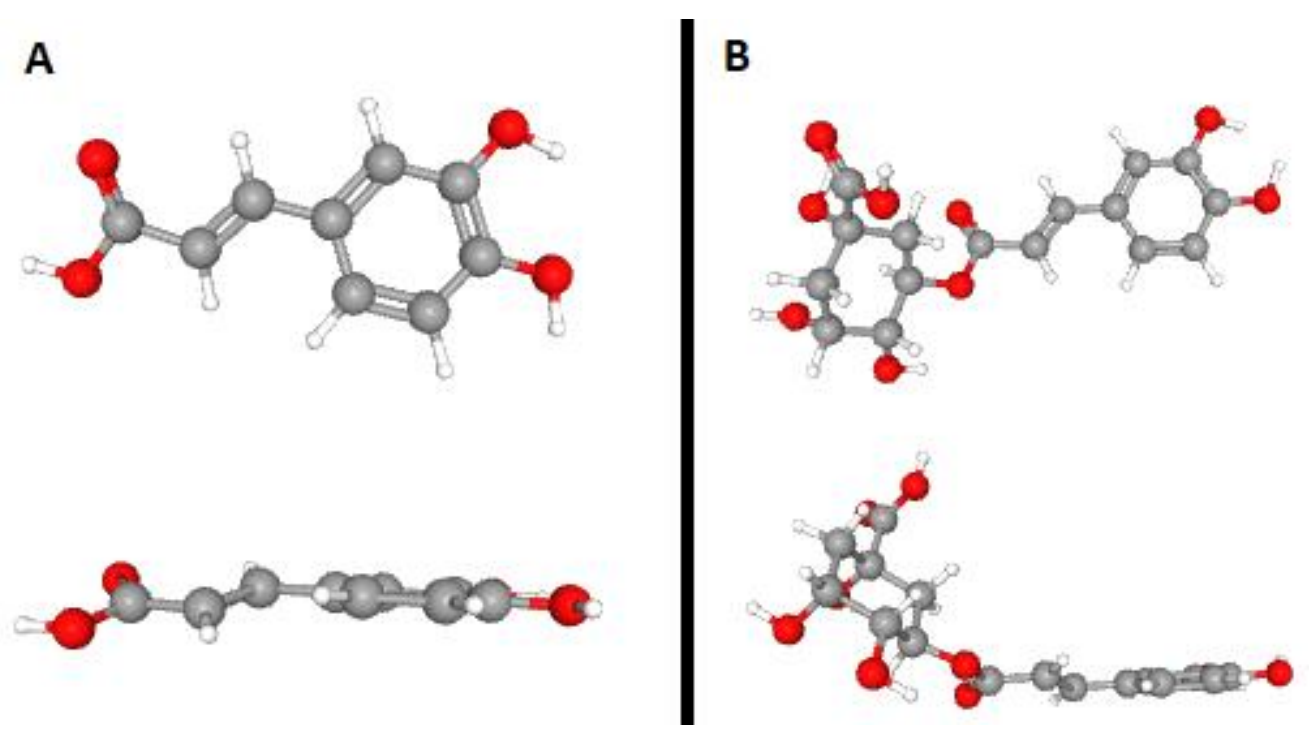

648

649

650

Figure 4. Chemical structure depiction of a) CA and b) CGA

651

652

653

654

655

656

657

658

659

660

661

662

663

664

665

666

667 
a)

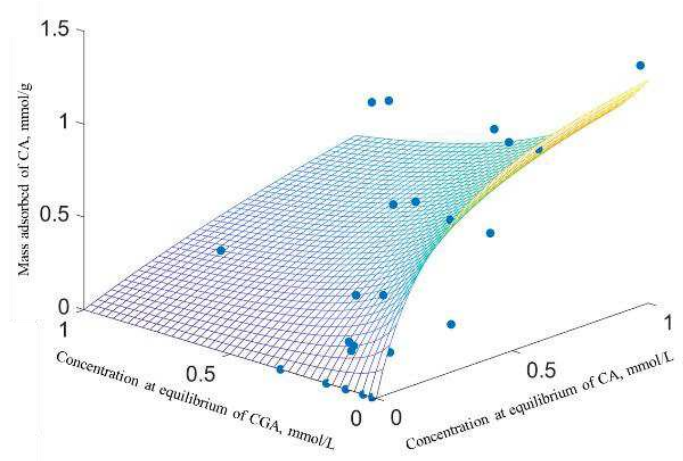

c)

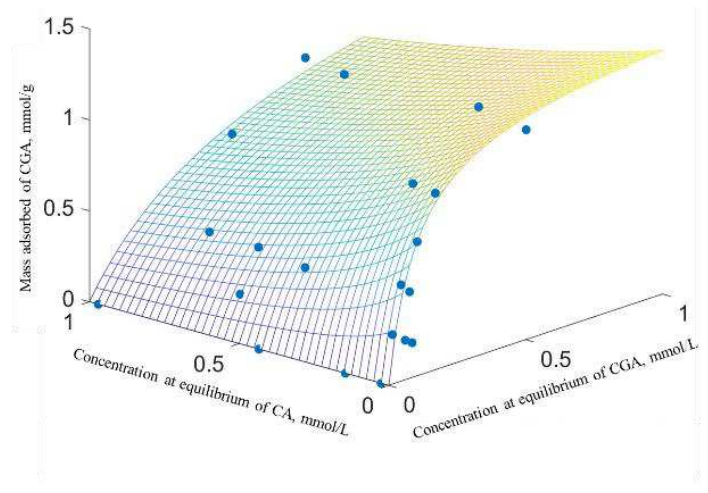

b)

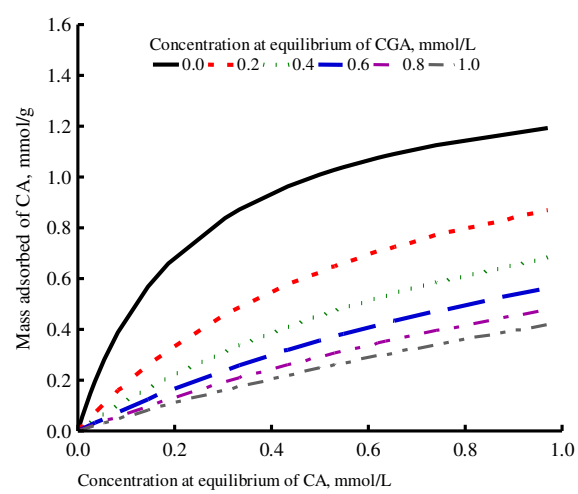

d)

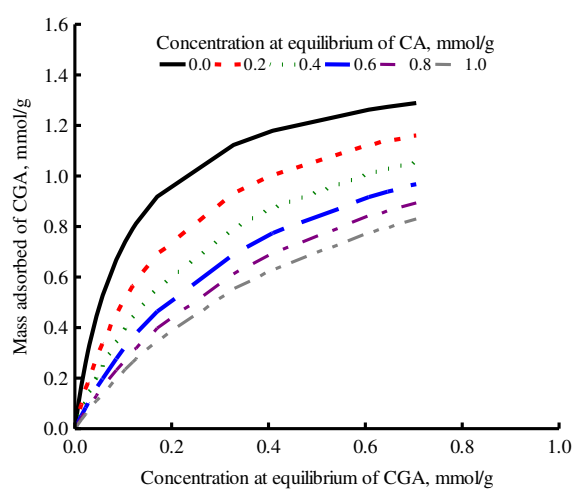


a)

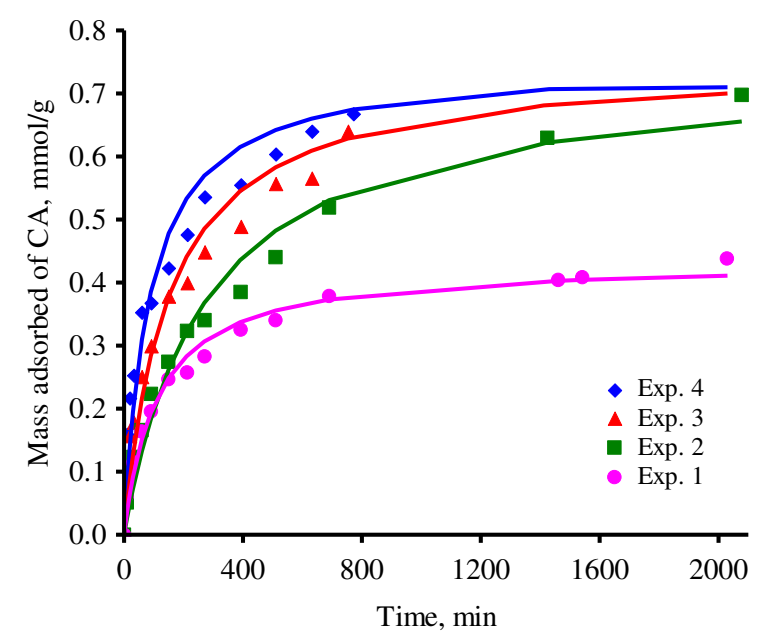

b)

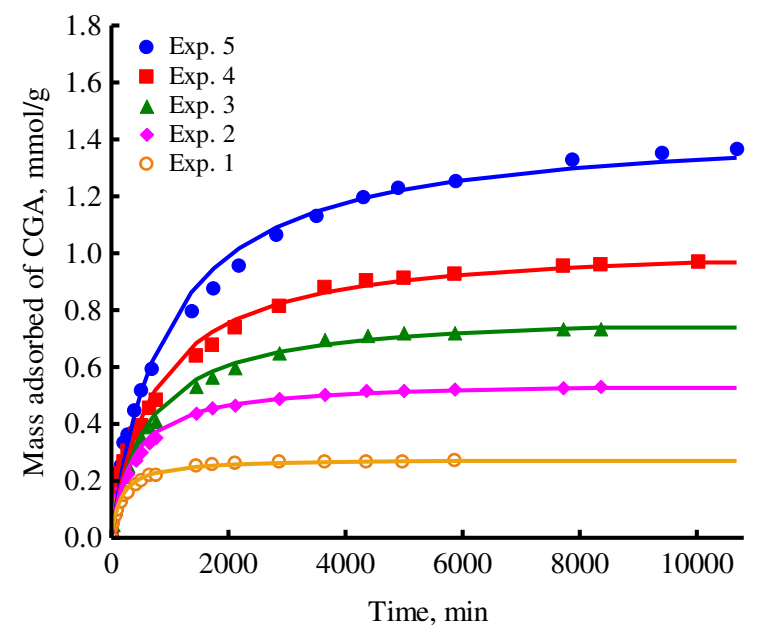

681 Figure 6. Adsorption kinetics of a) CA and b) CGA on GAC. The lines represent the 682 prediction of the second order kinetic model. 
a)

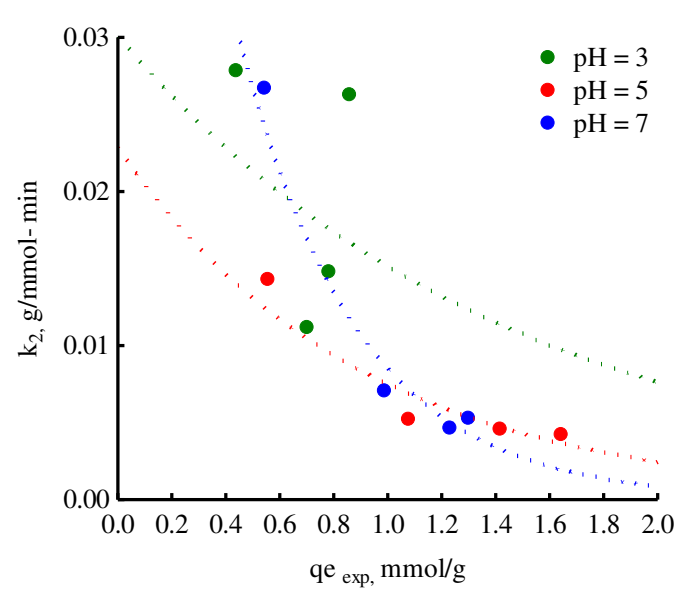

b)

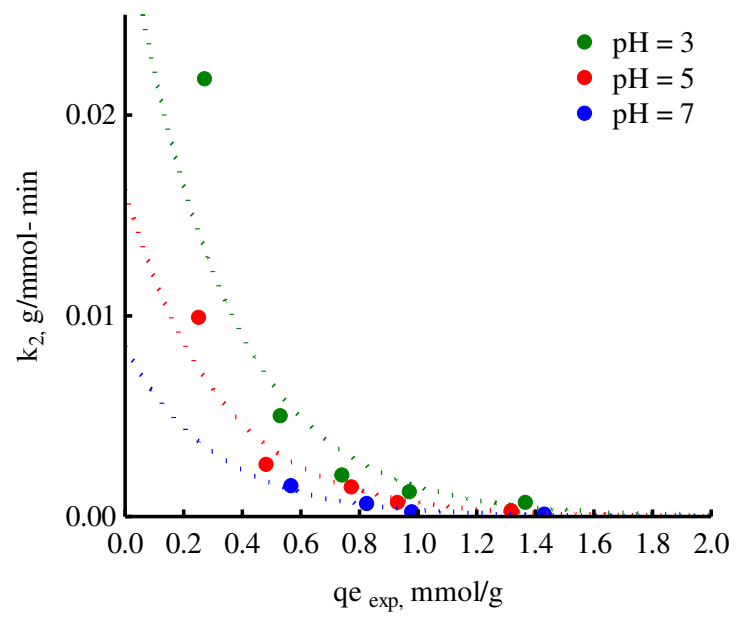

685

686 Figure 7. Variation of $\mathrm{k}_{2}$ with respect to the adsorption capacity as a function of $\mathrm{pH}$ for a)

$\mathrm{CA}$ and $\mathrm{b}$ ) CGA on $\mathrm{GAC}$ at $\mathrm{T}=25^{\circ} \mathrm{C}$.

688

689

690

691

692

693

694

695

696

697

698

699

700

701

702 
a)

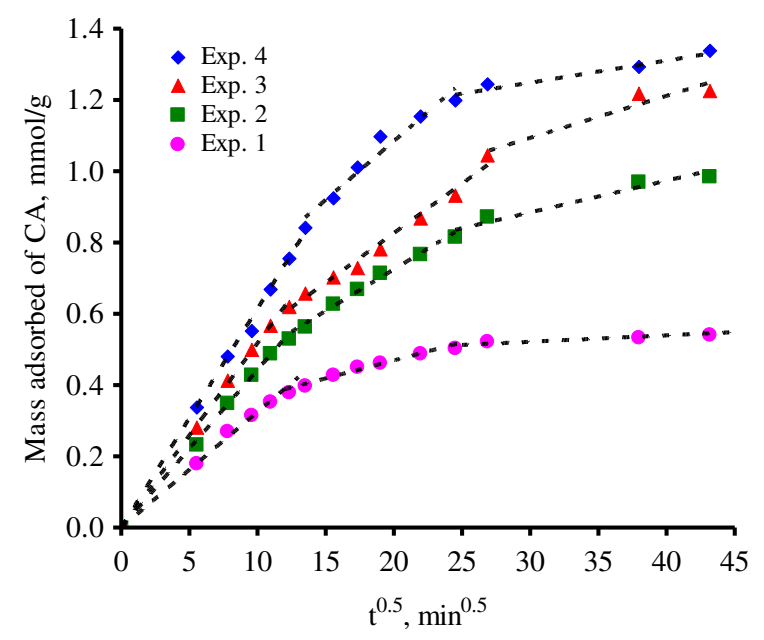

b)

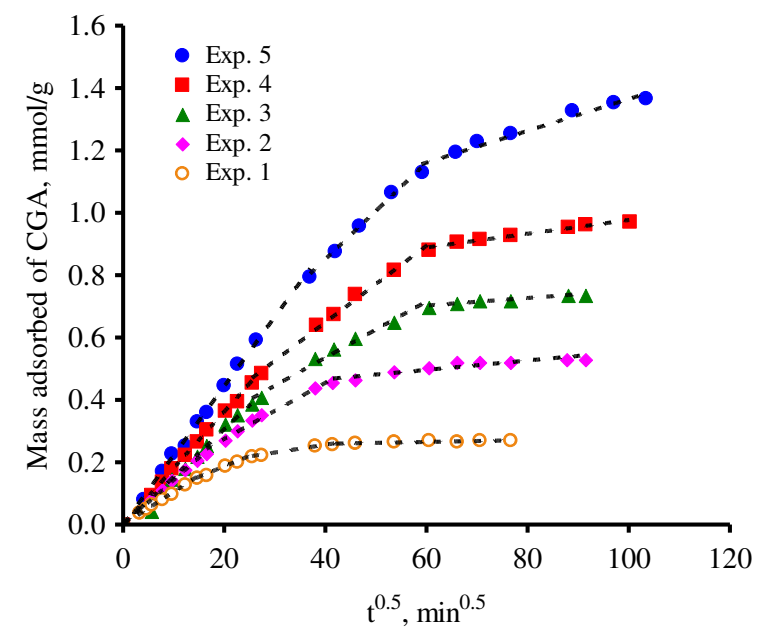

Figure 8. Adjustment parameters for the intraparticle diffusion model during the adsorption

705 of a) $\mathrm{CA}$ and b) $\mathrm{CGA}$ on $\mathrm{GAC}$ at $\mathrm{T}=25^{\circ} \mathrm{C}$.

706

707

708

709

710

711

712

713

714

715

716

717

718

719 


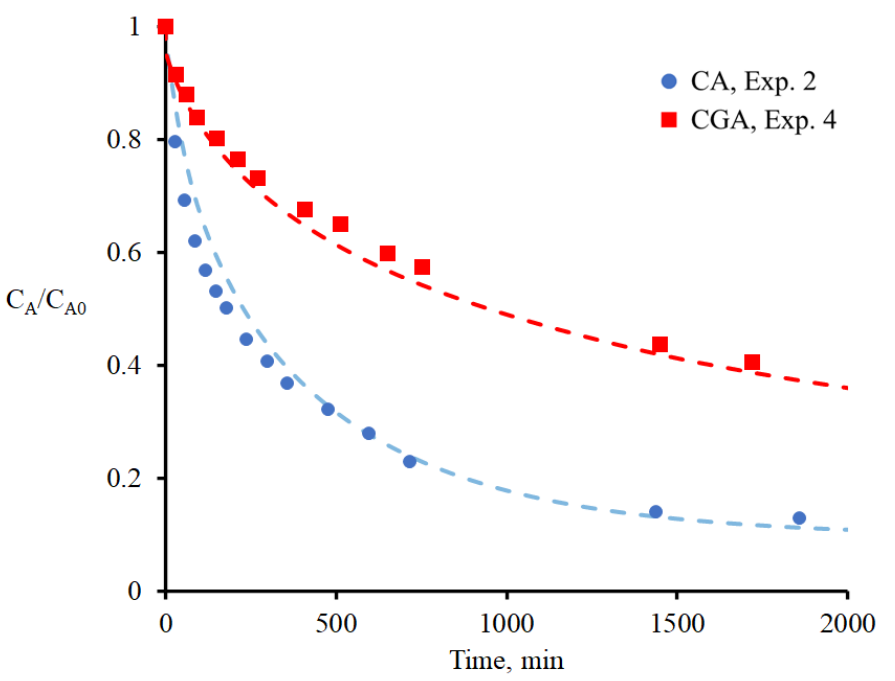

721

722 Figure 9. Decay curves of the concentration of CA and CGA, during the adsorption on GAC

723 at $\mathrm{T}=25^{\circ} \mathrm{C}$. The dotted line represents the PVSDM model prediction

724

725

726

727

728

729

730

731

732

733

734 


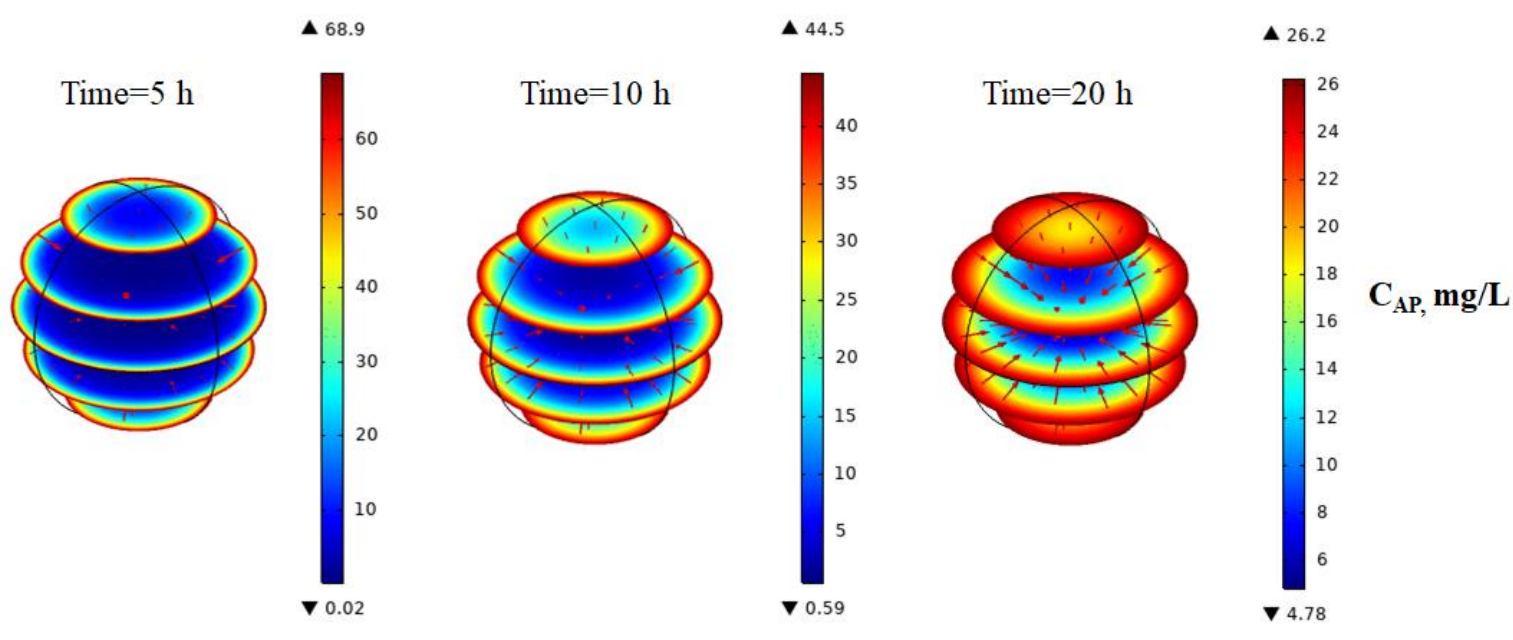

a)

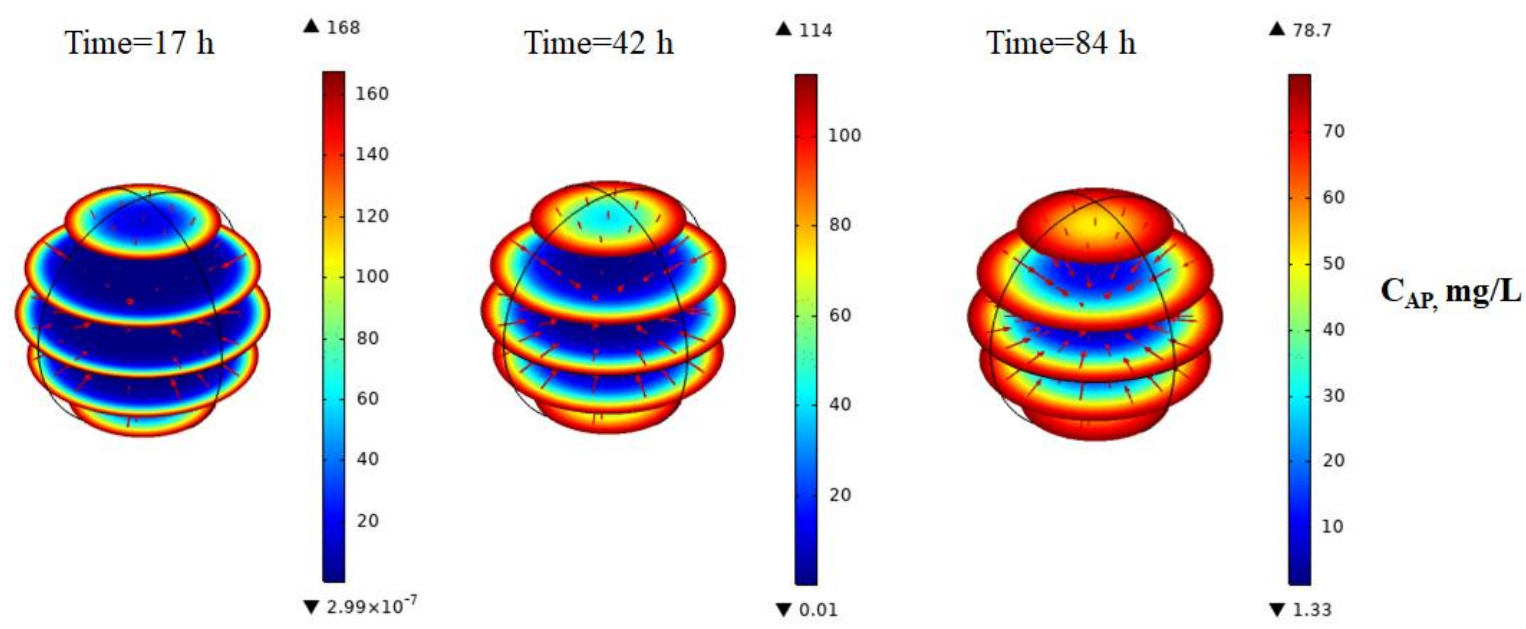

b)

735 Figure 10. Evolution of intraparticle concentration profiles as a function of time and position 736 for a) CA (Exp. 2) and b) CGA (Exp. 4). 


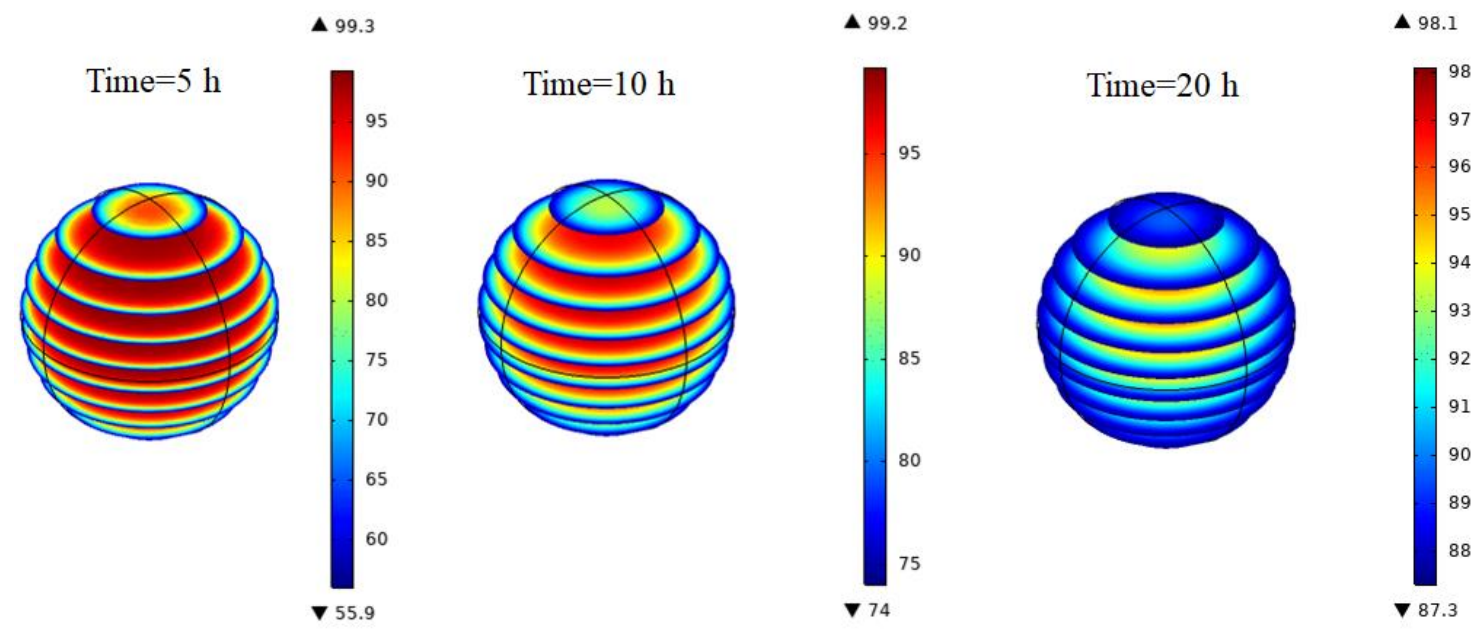

a)

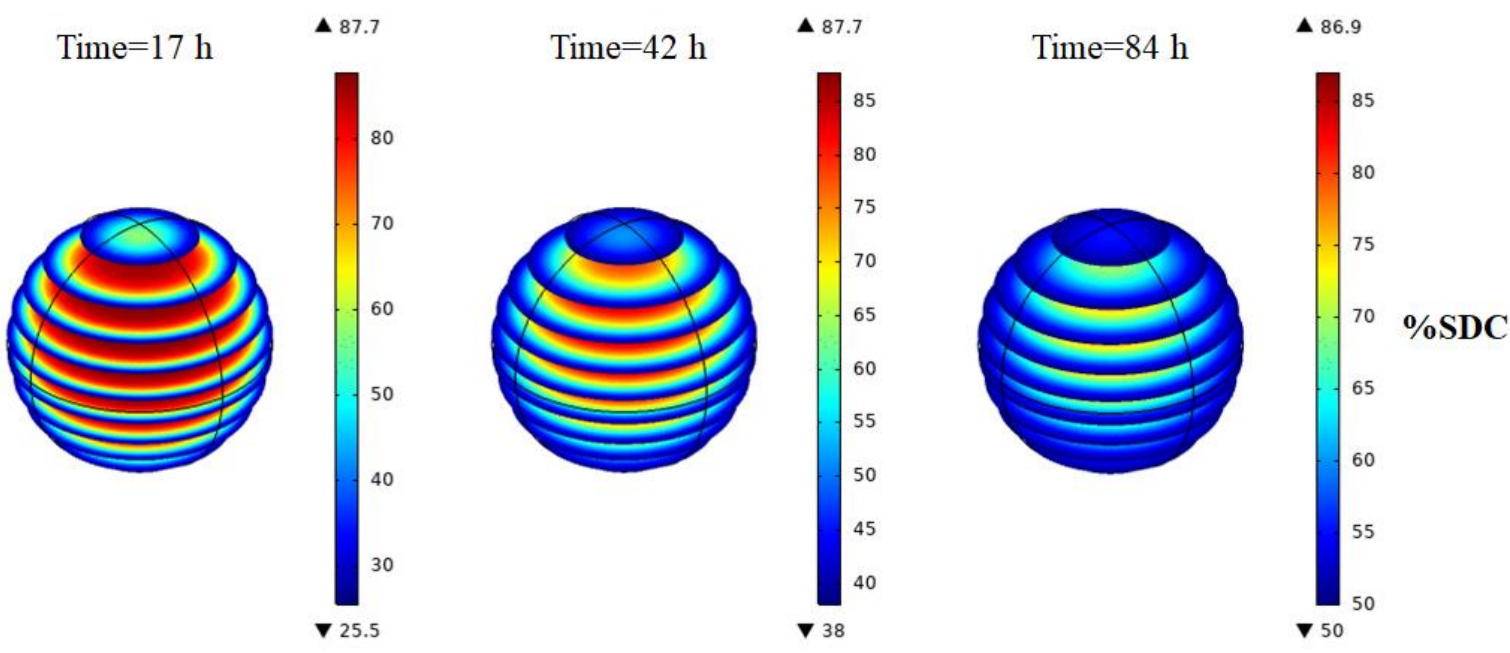

b)

739 Figure 11. Evolution of $\%$ SDC as a function of time and position during the adsorption of 740 a) CA (Exp. 2) and b) CGA (Exp. 4). 
a)

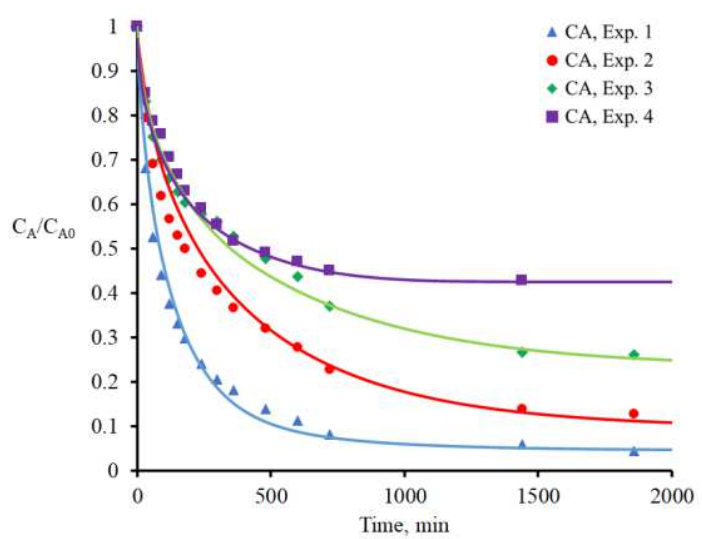

b)

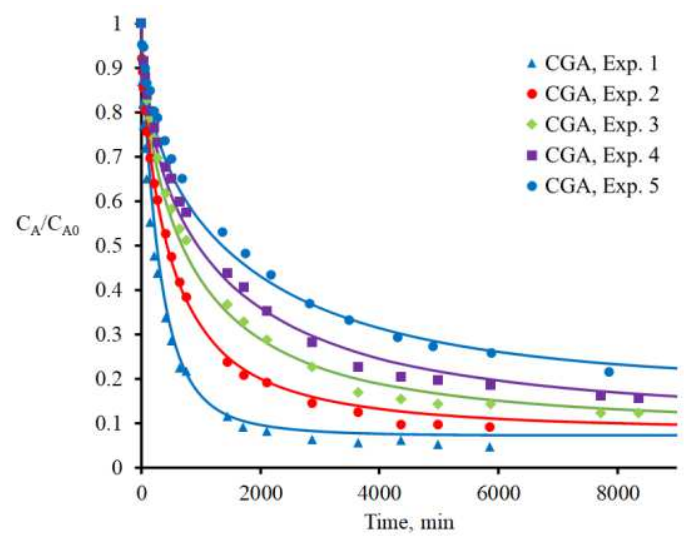

745 Figure 12. Decay curves of the concentration of a) CA and b) CGA during adsorption on GAC at $\mathrm{T}=25^{\circ} \mathrm{C}$. The solid line represents the prediction of the PVSDM model. 
Table 1. Physicochemical properties of phenolic acids (Pettersen et al. 2004; Mota et al. 2008; Uranga et al. 2016).

\begin{tabular}{|c|c|c|c|c|c|c|c|c|c|}
\hline Compound & $\begin{array}{c}\text { Molecular } \\
\text { Structure }\end{array}$ & $\begin{array}{l}\text { Molecular } \\
\text { Formula }\end{array}$ & $\begin{array}{c}\text { Molecular } \\
\text { Weight } \\
\text { (g/ mol) }\end{array}$ & $\begin{array}{c}\text { Solubility } \\
\text { mg / L }\end{array}$ & $\mathrm{pK}_{\mathrm{a}}$ & $\begin{array}{c}\mathrm{D}_{\mathrm{AB}} \times 10^{6} \\
\left(\mathrm{~cm}^{2} / \mathrm{s}\right)\end{array}$ & $\begin{array}{c}\text { Molecular } \\
\text { Size } \\
\AA\end{array}$ & $\begin{array}{c}\text { Volume } \\
\AA^{3}\end{array}$ & $\begin{array}{c}\text { Área } \\
\AA^{2}\end{array}$ \\
\hline \multirow{3}{*}{ CGA } & & \multirow{3}{*}{$\mathrm{C}_{16} \mathrm{H}_{18} \mathrm{O}_{9}$} & \multirow{3}{*}{354.311} & \multirow{3}{*}{400} & 3.6 & \multirow{3}{*}{4.95} & 17.815 & \multirow{3}{*}{283.21} & \multirow{3}{*}{298.84} \\
\hline & & & & & 8.5 & & 8.5425 & & \\
\hline & & & & & 11.2 & & 6.9818 & & \\
\hline \multirow{2}{*}{$\mathrm{CA}$} & & $\mathrm{C}_{9} \mathrm{H}_{8} \mathrm{O}_{4}$ & 180.160 & $\begin{aligned}< & 1000 \text { at } \\
& 22^{\circ} \mathrm{C}\end{aligned}$ & $\begin{array}{r}4.62 \\
8.69\end{array}$ & \multirow[t]{2}{*}{7.51} & $\begin{array}{l}12.136 \\
6.8537\end{array}$ & \multirow[t]{2}{*}{142.53} & \multirow[t]{2}{*}{169.35} \\
\hline & & & & 980 at $25^{\circ} \mathrm{C}$ & 11.2 & & 3.3191 & & \\
\hline
\end{tabular}


Table 2. Adjustment parameters of the $\mathrm{CA}$ and CGA for adsorption isotherms on $\mathrm{GAC}$ at $\mathrm{T}=25^{\circ} \mathrm{C}$.

\begin{tabular}{|c|c|c|c|c|c|c|c|}
\hline & \multirow{3}{*}{$\mathrm{pH}$} & \multicolumn{3}{|c|}{ Langmuir } & \multicolumn{3}{|c|}{ Freundlich } \\
\hline & & $\mathrm{q}_{\mathrm{m}}$ & $\mathrm{K}$ & \multirow[b]{2}{*}{$\mathrm{R}^{2}$} & \multicolumn{2}{|l|}{$\mathrm{K}$} & \multirow[b]{2}{*}{$\mathrm{R}^{2}$} \\
\hline & & $\mathrm{mmol} / \mathrm{g}$ & $\mathrm{L} / \mathrm{mmol}$ & & $\mathrm{mmol}^{1-1 / \mathrm{n}} \mathrm{L}^{1 / \mathrm{n}} \mathrm{g}^{-1}$ & $\mathrm{n}$ & \\
\hline \multirow{3}{*}{$\mathrm{AC}$} & 3 & 0.94 & 6.66 & 0.9996 & 0.81 & 3.80 & 0.9976 \\
\hline & 5 & 0.99 & 63.95 & 0.9933 & 1.04 & 6.15 & 0.9998 \\
\hline & 7 & 1.33 & 24.38 & 0.9991 & 1.38 & 4.68 & 0.9946 \\
\hline \multirow{3}{*}{ ACG } & 3 & 1.84 & 7.51 & 0.9926 & 2.37 & 2.00 & 0.9995 \\
\hline & 5 & 1.76 & 7.38 & 0.9856 & 2.24 & 1.97 & 0.9872 \\
\hline & 7 & 1.62 & 25.98 & 0.9062 & 2.28 & 2.85 & 0.9867 \\
\hline
\end{tabular}


Table 3. Adjustment parameters of the binary adsorption isotherms of $\mathrm{CA}$ and CGA on $\mathrm{GAC}$ at $\mathrm{T}=25^{\circ} \mathrm{C}$ and $\mathrm{pH}=3$.

\begin{tabular}{|c|c|c|c|c|}
\hline $\mathrm{q}_{\max }$ & $\mathrm{K}_{\mathrm{E}, \mathrm{ACG}}$ & $\mathrm{K}_{\mathrm{E}, \mathrm{AC}}$ & $\mathrm{q}, \mathrm{ACG}$ & $\mathrm{q}, \mathrm{AC}$ \\
\hline$(\mathrm{mmol} / \mathrm{g})$ & $(\mathrm{L} / \mathrm{mmol})$ & $(\mathrm{L} / \mathrm{mmol})$ & $\mathrm{R}^{2}$ & $\mathrm{R}^{2}$ \\
\hline 1.48 & 9.63 & 4.31 & 0.77 & 0.75 \\
\hline
\end{tabular}


Table 4. Operating conditions and adjustment parameters of the first and second order kinetic model during the adsorption of CA on $\mathrm{GAC}$ at $\mathrm{T}=25^{\circ} \mathrm{C}$.

\begin{tabular}{|c|c|c|c|c|c|c|c|c|c|}
\hline $\begin{array}{l}\text { No. } \\
\text { Exp. }\end{array}$ & $\mathbf{p H}$ & $\begin{array}{c}\mathrm{C}_{\mathrm{Ae}} \\
(\mathrm{mmol} / \mathrm{L})\end{array}$ & $\begin{array}{c}\mathbf{q}_{\mathrm{e}, \mathrm{exp}} \\
(\mathrm{mmol} / \mathrm{g})\end{array}$ & $\begin{array}{c}\mathrm{qe}_{\mathrm{e}} \\
(\mathrm{mmol} / \mathrm{g})\end{array}$ & $\begin{array}{c}\mathrm{k}_{1} \\
1 / \mathrm{min}\end{array}$ & $\mathbf{R}^{2}$ & $\begin{array}{c}\text { qe } \\
(\mathrm{mmol} / \mathrm{g})\end{array}$ & $\begin{array}{c}\mathbf{k}_{2} \\
(\mathrm{~g} / \mathrm{mmol}-\mathrm{min})\end{array}$ & $\mathbf{R}^{2}$ \\
\hline 1 & \multirow{4}{*}{3} & 0.57 & 0.44 & 0.3387 & $0.0096 \pm 0.0014$ & 0.9900 & 0.4008 & $0.0279 \pm 0.0043$ & 0.9966 \\
\hline 2 & & 1.11 & 0.70 & 0.4682 & $0.0062 \pm 0.0010$ & 0.9881 & 0.5792 & $0.0112 \pm 0.0024$ & 0.9941 \\
\hline 3 & & 1.69 & 0.78 & 0.5613 & $0.0081 \pm 0.0013$ & 0.9858 & 0.6590 & $0.0148 \pm 0.0031$ & 0.9936 \\
\hline 4 & & 2.20 & 0.86 & 0.5884 & $0.0131 \pm 0.0025$ & 0.9832 & 0.6643 & $0.0263 \pm 0.0052$ & 0.9933 \\
\hline 5 & \multirow{4}{*}{5} & 0.56 & 0.56 & 0.5080 & $0.0058 \pm 0.0008$ & 0.9881 & 0.5627 & $0.0143 \pm 0.0018$ & 0.9967 \\
\hline 6 & & 1.12 & 1.08 & 0.7732 & $0.0038 \pm 0.0004$ & 0.9897 & 0.8834 & $0.0052 \pm 0.0006$ & 0.9968 \\
\hline 7 & & 1.69 & 1.41 & 0.8858 & $0.0037 \pm 0.0005$ & 0.9862 & 1.0095 & $0.0046 \pm 0.0007$ & 0.9949 \\
\hline 8 & & 2.24 & 1.64 & 0.9931 & $0.0038 \pm 0.0006$ & 0.9841 & 1.1261 & $0.0043 \pm 0.0008$ & 0.9927 \\
\hline 9 & \multirow{4}{*}{7} & 0.57 & 0.54 & 0.5000 & $0.0105 \pm 0.0009$ & 0.9961 & 0.5557 & $0.0268 \pm 0.0009$ & 0.9998 \\
\hline 10 & & 1.13 & 0.98 & 0.8905 & $0.0058 \pm 0.0006$ & 0.9919 & 1.0247 & $0.0071 \pm 0.0006$ & 0.9985 \\
\hline 11 & & 1.66 & 1.23 & 1.0985 & $0.0048 \pm 0.0007$ & 0.9838 & 1.2706 & $0.0047 \pm 0.0008$ & 0.9939 \\
\hline 12 & & 2.27 & 1.30 & 1.2366 & $0.0065 \pm 0.0004$ & 0.9972 & 1.4519 & $0.0053 \pm 0.0004$ & 0.9990 \\
\hline
\end{tabular}


Table 5. Operating conditions and adjustment parameters of the first and second order kinetic model during the adsorption of CGA on $\mathrm{GAC}$ at $\mathrm{T}=25^{\circ} \mathrm{C}$.

\begin{tabular}{|c|c|c|c|c|c|c|c|c|c|}
\hline $\begin{array}{l}\text { No. } \\
\text { Exp. }\end{array}$ & pH & $\begin{array}{c}\mathrm{C}_{\mathrm{Ae}} \\
(\mathrm{mmol} / \mathrm{L})\end{array}$ & $\begin{array}{c}\text { qe,exp } \\
(\mathbf{m m o l} / \mathrm{g})\end{array}$ & $\begin{array}{c}\mathrm{qe} \\
(\mathrm{mmol} / \mathrm{g})\end{array}$ & $\begin{array}{c}\mathrm{k} 1 \\
1 / \mathrm{min}\end{array}$ & $\mathbf{R}^{2}$ & $\begin{array}{c}\mathrm{qe} \\
(\mathrm{mmol} / \mathrm{g})\end{array}$ & $\begin{array}{c}\text { k2 } \\
(\mathrm{g} / \mathrm{mmol}-\mathrm{min})\end{array}$ & $\mathbf{R}^{2}$ \\
\hline 1 & & 0.29 & 0.27 & 0.2581 & $0.0040 \pm 0.0004$ & 0.9908 & 0.2778 & $0.0218 \pm 0.0020$ & 0.9972 \\
\hline 2 & & 0.58 & 0.53 & 0.5007 & $0.0020 \pm 0.0002$ & 0.9922 & 0.5497 & $0.0050 \pm 0.0004$ & 0.9975 \\
\hline 3 & 3 & 0.84 & 0.74 & 0.6986 & $0.0013 \pm 0.0001$ & 0.9933 & 0.7930 & $0.0021 \pm 0.0001$ & 0.9985 \\
\hline 4 & & 1.14 & 0.97 & 0.9154 & $0.0011 \pm 0.0001$ & 0.9917 & 1.0402 & $0.0013 \pm 0.0001$ & 0.9971 \\
\hline 5 & & 1.69 & 1.37 & 1.2654 & $0.0008 \pm 0.0001$ & 0.9905 & 1.4522 & $0.0007 \pm 0.0001$ & 0.9970 \\
\hline 6 & & 0.27 & 0.25 & 0.2422 & $0.0023 \pm 0.0002$ & 0.9946 & 0.2762 & $0.0099 \pm 0.0009$ & 0.9979 \\
\hline 7 & & 0.55 & 0.48 & 0.4558 & $0.0011 \pm 0.0001$ & 0.9878 & 0.5217 & $0.0026 \pm 0.0004$ & 0.9938 \\
\hline 8 & 5 & 0.85 & 0.77 & 0.7382 & $0.0010 \pm 0.0001$ & 0.9940 & 0.8333 & $0.0015 \pm 0.0001$ & 0.9979 \\
\hline 9 & & 1.12 & 0.93 & 0.8991 & $0.0006 \pm 0.0001$ & 0.9893 & 1.0426 & $0.0007 \pm 0.0001$ & 0.9936 \\
\hline 10 & & 1.67 & 1.32 & 1.2849 & $0.0004 \pm 0.0001$ & 0.9842 & 1.5251 & $0.0003 \pm 0.0001$ & 0.9882 \\
\hline 11 & & 0.57 & 0.56 & 0.5538 & $0.0008 \pm 0.0001$ & 0.9952 & 0.6261 & $0.0016 \pm 0.0002$ & 0.9967 \\
\hline 12 & & 0.87 & 0.82 & 0.8004 & $0.0005 \pm 0.000039$ & 0.9948 & 0.9353 & $0.0007 \pm 0.0001$ & 0.9972 \\
\hline 13 & T & 1.13 & 0.98 & 0.9786 & $0.0003 \pm 0.000016$ & 0.9969 & 1.2469 & $0.0002 \pm 0.000022$ & 0.9975 \\
\hline 14 & & 1.69 & 1.43 & 1.4956 & $0.0002 \pm 0.000014$ & 0.9970 & 1.9992 & $0.0001 \pm 0.000012$ & 0.9970 \\
\hline
\end{tabular}


Table 6. Adjustment parameters of the intraparticle diffusion model during the adsorption of CA on $\mathrm{GAC}$ at $\mathrm{T}=25^{\circ} \mathrm{C}$.

\begin{tabular}{cccccccccccc}
\hline \multirow{2}{*}{$\begin{array}{c}\text { No. } \\
\text { Exp. }\end{array}$} & $\mathbf{p H}$ & \multicolumn{3}{c}{ Sección 1 } & \multicolumn{3}{c}{ Sección 2 } & \multicolumn{3}{c}{ Sección 3 } \\
\cline { 3 - 11 } & $\begin{array}{c}\mathbf{k}_{\mathbf{i}} \\
\mathbf{m m o l} / \mathbf{g}-\mathbf{h}^{\mathbf{0 . 5}}\end{array}$ & $\begin{array}{c}\mathbf{b}_{\mathbf{1}} \\
\mathbf{m m o l} / \mathbf{g}\end{array}$ & $\mathbf{R}^{\mathbf{2}}$ & $\begin{array}{c}\mathbf{k}_{\mathbf{i}} \\
\mathbf{m m o l} / \mathbf{g}-\mathbf{h}^{\mathbf{0 . 5}}\end{array}$ & $\begin{array}{c}\mathbf{b}_{\mathbf{2}} \\
\mathbf{m m o l} / \mathbf{g}\end{array}$ & $\mathbf{R}^{\mathbf{2}}$ & $\begin{array}{c}\mathbf{k}_{\mathbf{i}} \\
\mathbf{m m o l} / \mathbf{g}-\mathbf{h}^{\mathbf{0 . 5}}\end{array}$ & $\begin{array}{c}\mathbf{b}_{\mathbf{3}} \\
\mathbf{m m o l} / \mathbf{g}\end{array}$ & $\mathbf{R}^{\mathbf{2}}$ \\
\hline 1 & & 0.0205 & - & 0.9988 & 0.0098 & 0.1237 & 0.9857 & 0.003 & 0.2969 & 0.9213 \\
2 & & 0.0224 & - & 0.9935 & 0.0167 & 0.0701 & 0.9809 & 0.0093 & 0.2757 & 0.999 \\
3 & 3 & 0.0318 & - & 0.9958 & 0.0162 & 0.1766 & 0.9908 & - & - & - \\
4 & & 0.0467 & - & 0.9955 & 0.0165 & 0.2284 & 0.9901 & - & - & - \\
5 & & 0.0243 & - & 0.994 & 0.0077 & 0.244 & 0.9685 & 0.0022 & 0.4429 & 0.909 \\
6 & & 0.0293 & - & 0.995 & 0.0117 & 0.3052 & 0.989 & 0.0046 & 0.6867 & 0.9507 \\
7 & 5 & 0.033 & - & 0.9902 & 0.0144 & 0.315 & 0.9951 & 0.0078 & 0.7017 & 0.9788 \\
8 & & 0.0384 & - & 0.9836 & 0.0157 & 0.3754 & 0.9955 & 0.0101 & 0.7113 & 0.994 \\
9 & & 0.0325 & - & 0.9925 & 0.0101 & 0.2673 & 0.9673 & 0.0018 & 0.4676 & 0.8921 \\
10 & & 0.0443 & - & 0.9978 & 0.0233 & 0.2588 & 0.9884 & 0.0089 & 0.6176 & 0.9376 \\
11 & 7 & 0.0518 & - & 0.9983 & 0.0278 & 0.2706 & 0.9844 & 0.0118 & 0.7397 & 0.9283 \\
12 & & 0.0615 & - & 0.9972 & 0.0329 & 0.4267 & 0.955 & 0.0062 & 1.0627 & 0.8916 \\
\hline
\end{tabular}


Table 7. Adjustment parameters of the intraparticle diffusion model during the adsorption of CGA on $\mathrm{GAC}$ at $\mathrm{T}=25^{\circ} \mathrm{C}$.

\begin{tabular}{|c|c|c|c|c|c|c|c|c|c|}
\hline \multirow{2}{*}{$\begin{array}{l}\text { No. } \\
\text { Exp. }\end{array}$} & \multirow[b]{2}{*}{ pH } & \multicolumn{2}{|c|}{ Sección 1} & \multicolumn{3}{|c|}{ Sección 2} & \multicolumn{3}{|c|}{ Sección 3} \\
\hline & & $\begin{array}{c}\mathbf{k}_{\mathbf{i}} \\
\mathrm{mmol} / \mathrm{g}-\mathbf{h}^{0.5}\end{array}$ & $\mathbf{R}^{2}$ & $\begin{array}{c}\mathbf{k}_{\mathbf{i}} \\
\mathrm{mmol} / \mathrm{g}-\mathbf{h}^{0.5}\end{array}$ & $\begin{array}{c}\mathbf{b}_{2} \\
\mathrm{mmol} / \mathrm{g}\end{array}$ & $\mathbf{R}^{2}$ & $\begin{array}{c}\mathbf{k}_{\mathbf{i}} \\
\mathrm{mmol} / \mathrm{g}-\mathbf{h}^{0.5}\end{array}$ & $\begin{array}{c}\mathbf{b}_{3} \\
\mathrm{mmol} / \mathrm{g}\end{array}$ & $\mathbf{R}^{2}$ \\
\hline 1 & & 0.0105 & 0.9934 & 0.0045 & 0.0949 & 0.9279 & 0.0004 & 0.2408 & 0.8533 \\
\hline 2 & & 0.0143 & 0.9979 & 0.009 & 0.0948 & 0.9842 & 0.0015 & 0.4062 & 0.8706 \\
\hline 3 & 3 & 0.0153 & 0.9875 & 0.009 & 0.1755 & 0.9828 & 0.0012 & 0.6307 & 0.9516 \\
\hline 4 & & 0.0181 & 0.9981 & 0.0123 & 0.1565 & 0.992 & 0.0022 & 0.7567 & 0.967 \\
\hline 5 & & 0.0222 & 0.9956 & 0.0155 & 0.2311 & 0.9941 & 0.0051 & 0.8549 & 0.9633 \\
\hline 6 & & 0.0066 & 0.9918 & 0.0035 & 0.0832 & 0.9849 & 0.0007 & 0.208 & 0.8441 \\
\hline 7 & & 0.0093 & 0.9853 & 0.0076 & 0.0232 & 0.9864 & 0.0014 & 0.3599 & 0.9036 \\
\hline 8 & 5 & 0.0133 & 0.9982 & 0.0054 & 0.3652 & 0.9547 & 0.0015 & 0.6202 & 0.9701 \\
\hline 9 & & 0.013 & 0.9962 & 0.0027 & 0.6605 & 0.961 & - & - & - \\
\hline 10 & & 0.0177 & 0.8428 & 0.0148 & 0.0176 & 0.997 & 0.0048 & 0.7747 & 0.9343 \\
\hline 11 & & 0.0087 & 0.9964 & 0.0069 & 0.0943 & 0.9905 & 0.0008 & 0.4868 & 0.8373 \\
\hline 12 & 7 & 0.0102 & 0.9953 & 0.0116 & 0.0385 & 0.9976 & 0.0024 & 0.5664 & 0.9689 \\
\hline 13 & & 0.0076 & 0.9596 & 0.0114 & 0.0899 & 0.9971 & 0.0035 & 0.5676 & 0.9789 \\
\hline 14 & & 0.009 & 0.922 & 0.0164 & 0.1914 & 0.9951 & 0.0062 & 0.7097 & 0.9218 \\
\hline
\end{tabular}


Table 8. Adjustment parameters of the PVSDM model during the adsorption of CA on GAC with $\mathrm{rp}=0.051 \mathrm{~cm}$ at $200 \mathrm{RPM}$ and at $\mathrm{T}$ $=25^{\circ} \mathrm{C}$.

\begin{tabular}{ccccccc}
\hline No. Exp. & $\mathbf{p H}$ & $\begin{array}{c}\mathbf{C}_{\mathbf{A 0}} \\
(\mathbf{m g} / \mathbf{L})\end{array}$ & $\begin{array}{c}\mathbf{C}_{\mathbf{A e}} \\
(\mathbf{m g} / \mathbf{L})\end{array}$ & $\begin{array}{c}\mathbf{q}_{\mathbf{e}, \mathbf{e x p}} \\
(\mathbf{m g} / \mathbf{g})\end{array}$ & $\begin{array}{c}\mathbf{k}_{\mathbf{L}} \times \mathbf{1 0}^{\mathbf{3}} \\
(\mathbf{c m} / \mathbf{s})\end{array}$ & $\begin{array}{c}\mathbf{D}_{\mathbf{s}} \times \mathbf{1 0} \mathbf{9}^{\mathbf{2}} \\
\left(\mathbf{c m}^{\mathbf{2}} / \mathbf{s}\right)\end{array}$ \\
\hline 1 & & 102.78 & 23.88 & 78.88 & 3.44 & 4.53 \\
2 & 3 & 200.33 & 74.50 & 125.76 & 1.44 & 5.04 \\
3 & & 304.62 & 163.60 & 140.88 & 1.92 & 6.32 \\
4 & & 396.98 & 242.16 & 154.60 & 2.27 & 15.3 \\
5 & & 101.47 & 1.36 & 98.27 & 3.68 & 7.06 \\
6 & 201.75 & 8.04 & 193.70 & 1.45 & 5.15 \\
7 & 5 & 303.87 & 49.17 & 254.67 & 1.03 & 5.10 \\
8 & & 402.98 & 107.04 & 295.83 & 1.04 & 5.57 \\
9 & & 102.36 & 4.60 & 97.76 & 3.11 & 4.65 \\
10 & & 203.55 & 26.09 & 177.44 & 3.00 & 3.17 \\
11 & 7 & 299.35 & 78.04 & 221.24 & 2.80 & 4.00 \\
12 & & 408.32 & 174.69 & 233.47 & 2.60 & 4.63 \\
\hline
\end{tabular}


Table 9. Adjustment parameters of the PVSDM model during the adsorption of ACG on CAG with rp $=0.051 \mathrm{~cm}$ at $200 \mathrm{RPM}$ and at T $=25^{\circ} \mathrm{C}$.

\begin{tabular}{|c|c|c|c|c|c|c|}
\hline No. Exp. & $\mathbf{p H}$ & $\begin{array}{c}\mathrm{C}_{\mathrm{A0}} \\
(\mathrm{mg} / \mathrm{L})\end{array}$ & $\begin{array}{c}\mathrm{C}_{\mathrm{Ae}} \\
(\mathrm{mg} / \mathrm{L})\end{array}$ & $\begin{array}{c}\mathbf{q}_{\mathrm{e}, \exp } \\
(\mathrm{mg} / \mathrm{g})\end{array}$ & $\begin{array}{c}\mathrm{k}_{\mathrm{L}} \times 10^{-4} \\
(\mathrm{~cm} / \mathrm{s})\end{array}$ & $\begin{array}{l}D_{\mathrm{s}} \times 10^{10} \\
\left(\mathrm{~cm}^{2} / \mathrm{s}\right)\end{array}$ \\
\hline 1 & \multirow{5}{*}{3} & 101.30 & 4.74 & 96.56 & 9.40 & 7.81 \\
\hline 2 & & 203.83 & 15.84 & 187.99 & 9.20 & 5.79 \\
\hline 3 & & 298.15 & 36.78 & 261.37 & 9.00 & 4.74 \\
\hline 4 & & 404.23 & 60.27 & 343.96 & 8.80 & 3.89 \\
\hline 5 & & 600.20 & 116.12 & 484.08 & 8.60 & 6.11 \\
\hline 6 & \multirow{5}{*}{5} & 95.47 & 6.89 & 88.58 & 10.5 & 12.6 \\
\hline 7 & & 193.87 & 24.21 & 169.66 & 1.84 & 2.50 \\
\hline 8 & & 299.75 & 26.08 & 273.67 & 1.91 & 8.80 \\
\hline 9 & & 398.58 & 68.62 & 329.96 & 1.36 & 7.96 \\
\hline 10 & & 590.15 & 122.98 & 467.17 & 6.77 & 6.32 \\
\hline 11 & \multirow{4}{*}{7} & 200.36 & 0.29 & 198.17 & 1.81 & 2.04 \\
\hline 12 & & 308.17 & 15.97 & 292.21 & 1.36 & 6.32 \\
\hline 13 & & 398.74 & 52.19 & 346.55 & 8.87 & 3.00 \\
\hline 14 & & 597.22 & 90.27 & 506.95 & 7.32 & 4.00 \\
\hline
\end{tabular}

